Supporting information

\title{
Development of Strategies for the Regiocontrolled Synthesis of meso-
}

\section{5,10,20-Triaryl-2,3-chlorins}

Marilyne Varamo, Bernard Loock, Philippe Maillard and David S. Grierson.

UMR 176 CNRS/Institut Curie, Institut Curie, Bât 110, Centre Universitaire, Université Paris-Sud XI, F-91405

Orsay, France.

All solvents used were reagent grade. Methylene chloride was distilled from calcium hydride and kept over activated $4 \AA$ sieves. Dimethylformamide was distilled under slow argon flow and kept over activated $4 \AA$ sieves. Pyridine was distilled under KOH. Column chromatography was performed with the indicated solvents using E. Merck silica gel 60 (particle size 0.035-0.070 $\mathrm{mm}$ ). Macherey-Nagel precoated plates (SIL G-200, $2 \mathrm{~mm}$ ) were used for preparative thin-layer chromatography. Yields refer to chromatographically and spectroscopically pure compounds. All compounds were characterized by ${ }^{1} \mathrm{H}$ and ${ }^{13} \mathrm{C}$ NMR spectra (HMQC, HMBC and 1D Nuclear Overhauser Difference Spectroscopy) recorded on a Bruker AC-300 spectrometer at ambient temperature using an internal deuterium lock. Chemical shift values are given in ppm relative to tetramethyl silane (TMS). Acidic impurities in $\mathrm{CDCl}_{3}$ were removed by treatment with anhydrous $\mathrm{K}_{2} \mathrm{CO}_{3}$. Quantitative UV-visible spectra were obtained using a Varian DMS 200 spectrometer. ESI mass spectra were obtained by infusion using a ZQ 2000 waters mass spectrometer. Microanalyses were performed by the ICSN-CNRS Elemental Analysis Center at Gif-sur-Yvette, France.

5,15-di(4-isopropyloxyphenyl)porphyrin : 5b Dry methylene chloride (3.7 L) was placed in a three-necked flask equipped with magnetic stirrer, gas inlet (argon) and a reflux condenser. Dipyrromethane 4 (2.23 g, $15.2 \mathrm{mmol})$ and 4-isopropyloxybenzaldehyde (2.5 g, $15.2 \mathrm{mmol})$ were added. The flask was shielded from ambient light and then $0.256 \mathrm{~mL}(3.32 \mathrm{mmol})$ of trifluoroacetic acid in dry methylene chloride $(100 \mathrm{~mL})$ were added and the reaction mixture stirred for $18 \mathrm{~h}$ at $20^{\circ} \mathrm{C}$. Subsequently, $5 \mathrm{~g}(22 \mathrm{mmol})$ of DDQ suspended in dry methylene chloride $(100 \mathrm{~mL})$ were added and the mixture was stirred for $1 \mathrm{~h}$. Then, triethylamine (11 $\mathrm{mL})$ were added and the reaction mixture was filtered through a silica gel column $(740 \mathrm{~mL})$. Silica gel was washed with chloroform until the washing solution becomes nearly colorless. The red solution was concentrated under vacuum. The crude product was crystallized from a mixture of methylene chloride and methanol. The filtrate was washed with methanol and dried in vacuum at $100^{\circ} \mathrm{C}$ for 5 hours to yield $2.38 \mathrm{~g} \mathrm{(54 \% )} \mathrm{of} \mathrm{the} \mathrm{title} \mathrm{compound} \mathrm{as} \mathrm{a} \mathrm{purple}$ amorphous solid. $\left(\mathrm{Rf}=0.51, \mathrm{SiO}_{2}\right.$, toluene). Anal. $\left(\mathrm{C}_{38} \mathrm{H}_{36} \mathrm{~N}_{4} \mathrm{O}_{2}\right)$ calc. C 78.59, H $6.25 \mathrm{~N}$ 
9.65, found C 78.34, H 5.81, N 8.91. UV-vis spectrum in $\mathrm{CH}_{2} \mathrm{Cl}_{2}: \lambda_{\max }, \mathrm{nm}\left(\varepsilon \mathrm{L} . \mathrm{mmol}^{-1} . \mathrm{cm}^{-}\right.$ $\left.{ }^{1}\right)$ : 410.5 (326.3), 505.5 (15.3), 541.5 (7.2), 578.5 (5.1), 634 (2.2). ${ }^{1} \mathrm{H}$ NMR $\left(\mathrm{CDCl}_{3}\right) \delta(\mathrm{ppm})$ : 10.30 (s, 2H, H-10, 20), 9.39 (d, 4H, $J=4.6$ Hz, H-pyr), 9.13 (d, 4H, J=4.6 Hz, H-pyr), 8.17 (d, 4H, $J=8.5 \mathrm{~Hz}, \mathrm{H}-o$-phenoxy), 7.33 (d, 4H, $J=8.6 \mathrm{~Hz}, \mathrm{H}-m$-phenoxy), 4.90 [sept, $\left.2 \mathrm{H}, J=6.0 \mathrm{~Hz}, \mathrm{C} \underline{\mathrm{H}}\left(\mathrm{CH}_{3}\right)_{2}\right], 1.60\left[\mathrm{~d}, 12 \mathrm{H}, J=6.0 \mathrm{~Hz}, \mathrm{CH}\left(\mathrm{C}_{3}\right)_{2}\right],-3,07$ (s, 2H, NH). ${ }^{13} \mathrm{C}$ NMR $\left(\mathrm{CDCl}_{3}\right) \delta(\mathrm{ppm}): 157.9$ (C-p-phenoxy), 148 (C-4, 6, 14, 16), 145 (C-1, 9, 11, 19), 136.10 (C-o-phenoxy), 133.6 (C-1, C-phenoxy), 131.5 (C-2, 3, 7, 8, 12, 13, 17, 18), 119.2 (C5, C-15), 114.50 (C-m-phenoxy), 105.31 (C-10, C-20), 70.50 [-O- $\left.\underline{\mathrm{CH}}\left(\mathrm{CH}_{3}\right)_{2}\right], 22.40$ [-O$\left.\mathrm{CH}\left(\underline{\mathrm{CH}}_{3}\right)_{2}\right]$.

5,15-di(4-isopropyloxyphenyl)-10-(4-hydroxyphenyl)porphyrin: $n$-Butyl lithium (12 $\mathrm{mL}$ of a 1.6 M solution in $n$-hexane, $19.2 \mathrm{mmol}$ ) was added under an argon atmosphere to a dry Schlenk flask charged with a solution of $p$-bromophenol $(1.73 \mathrm{~g}, 10 \mathrm{mmol})$ in $15 \mathrm{ml}$ of dry diethyl ether at $0{ }^{\circ} \mathrm{C}$. After addition of $n$-butyl lithium, the cold bath was removed and stirring was continued for $18 \mathrm{~h}$ at room temperature. The solution slowly became beige opaque. To this vigorously stirred mixture was added rapidly a solution of 5,15-di( $p$ isopropyloxyphenyl)porphyrin $\mathbf{5 b}(289 \mathrm{mg}, 0.5 \mathrm{mmol})$ in $100 \mathrm{ml}$ of dry tetrahydrofurane (THF) under an argon atmosphere. The color of the mixture changed from deep purple to brown green. The solution was stirred during two hours. The end of the reaction was checked by thin layer chromatography (silica gel, toluene). A mixture of water and THF ( $2 \mathrm{~mL}, 100$ $\mathrm{mL}$ ) was added for the hydrolysis and the solution was stirred for $15 \mathrm{~min}$. (green solution). The oxidation of the mixture was performed by air bubbling for one hour (deep purple solution) and the solution was concentrated under vacuum. The crude product was dissolved in methylene chloride, chromatographied on silica gel column eluted with methylene chloride, yielded $294 \mathrm{mg}(87 \%)$ of porphyrin as purple crystals used without purification. Anal. $\left(\mathrm{C}_{44} \mathrm{H}_{38} \mathrm{~N}_{4} \mathrm{O}_{3}\right), 0.5 \mathrm{H}_{2} \mathrm{O}$ calc. C 77.74, $\mathrm{H}$ 5.78, N 8.24, found C 77.71, H 5.51, N 8.32. UV-vis spectrum in $\mathrm{CH}_{2} \mathrm{Cl}_{2}: \lambda_{\max }, \mathrm{nm}\left(\varepsilon \mathrm{L} \cdot \mathrm{mmol}^{-1} \cdot \mathrm{cm}^{-1}\right): 416$ (415.4), 512 (16.7), 548 (8.1), 586 (5.1), 642 (3.5). ${ }^{1} \mathrm{H}$ NMR $\left(\mathrm{CDCl}_{3}\right) \delta(\mathrm{ppm}): 10.18$ (s, 1H, H-20), 9.32 (d, 2H, J=4.6 Hz, H2, 18-pyr), 9.06 (d, 2H, $J=4.6 \mathrm{~Hz}, \mathrm{H}-3,17), 8.94$ (d, 2H, $J=4.8 \mathrm{~Hz}, \mathrm{H}-7,13 / 8,12), 8.88$ (d, $2 \mathrm{H}, J=4.8 \mathrm{~Hz}, \mathrm{H}-7,13 / 8,12), 8.12$ (d, 4H, $J=8.6 \mathrm{~Hz}, \mathrm{H}-o$-phenoxy), 8.06 (d, 2H, $J=8.5$ Hz, H, o-hydroxyphenyl), 7.29 (d, 4H, $J=8.6 \mathrm{~Hz}, \mathrm{H}-m$-phenoxy), 7.18 (d, 2H, $J=8.5 \mathrm{~Hz}, \mathrm{H}$, $m$-hydroxyphenyl), 5.04 (s, 1H, OH), 4.87 [sept, $\left.2 \mathrm{H}, J=6.0 \mathrm{~Hz}, \mathrm{C} \underline{\mathrm{H}}\left(\mathrm{CH}_{3}\right)_{2}\right], 1.58$ [d, $J=6.0$ $\left.\mathrm{Hz}, 6 \mathrm{H}, \mathrm{CH}\left(\mathrm{CH}_{3}\right)_{2}\right],-2.98$ (s, 2H, NH). ${ }^{13} \mathrm{C} \mathrm{NMR}\left(\mathrm{CDCl}_{3}\right) \delta(\mathrm{ppm}): 157.79$ (C-p-phenoxy), 
155.38 (C-p-hydroxyphenyl), 147.2 (C-4, 6, 9, 11, 14, 16), 145.6 (C-1, 19), 135.82 (C-ophenoxy), 135.67 (C-o-hydroxyphenyl), 135.27 (C-1, C-hydroxyphenyl), 133.92 (C-1, Cphenoxy), 131 (very broad, C-2, 3, 7, 8, 12, 13, 17, 18), 119.47 (C-5, C-10, C-15), 114.15 (C$m$-phenoxy), 113.54 (C-m-hydroxyphenyl), 104.69 (C-20), 70.21 [-O- $\left.\underline{\mathrm{CH}}\left(\mathrm{CH}_{3}\right)_{2}\right], 22.35$ [-O$\left.\mathrm{CH}\left(\mathrm{CH}_{3}\right)_{2}\right]$.

5,10,15-tri(4-isopropyloxyphenyl)porphyrin : 13 A mixture of 5,15-di(4-isopropyloxyphenyl)-10-(4-hydroxyphenyl)porphyrin $(290 \mathrm{mg}, 0.43 \mathrm{mmol})$, potassium carbonate (1.38 $\mathrm{g}$, $10 \mathrm{mmol})$ and isopropyl bromide $(2.5 \mathrm{~mL}, 26.6 \mathrm{mmol})$ in dimethylformamide $(50 \mathrm{~mL})$ was stirred at $50-55^{\circ} \mathrm{C}$ overnight under argon. The solution was concentrated under vacuum. The crude product was diluted in toluene, filtered, evaporated then crystallized from a mixture of methyl chloride-methanol. The title compound was obtained as purple crystals (yield $259 \mathrm{mg}$, 84 \%). Anal. $\left(\mathrm{C}_{47} \mathrm{H}_{44} \mathrm{~N}_{4} \mathrm{O}_{3}\right), 0.5 \mathrm{H}_{2} \mathrm{O}$ calc. C 78.20, H 6.28, N 7.76, found $\mathrm{C} 78.34, \mathrm{H} 6.02, \mathrm{~N}$ 7.71. UV-vis spectrum in $\mathrm{CH}_{2} \mathrm{Cl}_{2}: \lambda_{\max }, \mathrm{nm}\left(\varepsilon \mathrm{L}_{\mathrm{mmol}}{ }^{-1} . \mathrm{cm}^{-1}\right): 416$ (414.7), 512 (16.8), 548.5 (8.4), 586 (5.1), 641.5 (3.6). ${ }^{1} \mathrm{H}$ NMR $\left(\mathrm{CDCl}_{3}\right) \delta(\mathrm{ppm}): 10.11$ (s, 1H, H-20), $9.26(\mathrm{~d}$, $2 \mathrm{H}, J=4.6 \mathrm{~Hz}, \mathrm{H}-2,18), 9.03$ (d, 2H, $J=4.6 \mathrm{~Hz}, \mathrm{H}-3,17), 8.93$ (d, 2H, $J=4.8 \mathrm{~Hz}, \mathrm{H}-7,13 / 8$ 12), 8.90 (d, 2H, $J=4.8$ Hz, H-7, 13/8,12), 8.09 (d, 4H, $J=8.3$ Hz, H-5, H-15, H-o-phenoxy), 8.07 (d, 2H, $J=8.0 \mathrm{~Hz}, \mathrm{H}-10, \mathrm{H}-o$-phenoxy), 7.24 (d, 4H, $J=8.7 \mathrm{~Hz}, \mathrm{H}-5, \mathrm{H}-15, \mathrm{H}-m-$ phenoxy), 7.21 (d, 2H, $J=9.0 \mathrm{~Hz}, \mathrm{H}-10, \mathrm{H}-m$-phenoxy), 4.80 [sept, 2H, $J=6 \mathrm{~Hz}, \mathrm{H}-5,15$, $\left.\mathrm{CH}\left(\mathrm{CH}_{3}\right)_{2}\right], 4.79$ (sept, $\left.1 \mathrm{H}, J=6 \mathrm{~Hz}, \mathrm{H}-10,-\mathrm{C} \underline{\mathrm{H}}\left(\mathrm{CH}_{3}\right)_{2}\right), 1.53$ [d, 12H, $J=6.0 \mathrm{~Hz}, \mathrm{H}-5,15$, $\left.\mathrm{CH}\left(\mathrm{CH}_{3}\right)_{2}\right], 1.52$ [d, $\left.6 \mathrm{H}, J=6.0 \mathrm{~Hz}, \mathrm{H}-10,-\mathrm{CH}\left(\mathrm{CH}_{3}\right)_{2}\right],-2.96$ (s. $\left.2 \mathrm{H}, \mathrm{NH}\right) .{ }^{13} \mathrm{C} \mathrm{NMR}\left(\mathrm{CDCl}_{3}\right)$ $\delta(\mathrm{ppm}): 157.72$ (C-p-phenoxy), 157.68 (C-p-phenoxy), 147.18-145.76 (C-1, 4, 6, 9, 11, 14, 16, 19), 135.79 (C-o-phenoxy), 135.62 (C-o-phenoxy), 134.77 (C-1-phenoxy), 133.90 (C-1phenoxy), 131.41-130.59 (C-2, 3, 7, 8, 12, 13, 17, 18), 120.47 (C-10), 119.40 (C-5, C-15), 114.09 (C-m-phenoxy), 113.77 (C-m-phenoxy), 104.43 (C-20), 70.12 [-O- $\left.\underline{\mathrm{C}}\left(\mathrm{CH}_{3}\right)_{2}\right], 22.30$ $\left[-\mathrm{O}-\mathrm{CH}\left(\mathrm{CH}_{3}\right)_{2}\right]$.

\section{General procedure for the synthesis of chlorins}

The porphyrin (1 eq.) and anhydrous potassium carbonate (9 eq.) were dissolved in dry pyridine. $p$-Toluenesulfonhydrazide ( 2 eq.) in dry pyridine was added. The mixture was heated at $100-105^{\circ} \mathrm{C}$ under argon for 24 hours. Further quantities of $p$-toluenesulfonhydrazide ( 2 eq. in dry pyridine) were added after 2, 4, 6 and 8 hours. After cooling, the mixture was treated with ethyl acetate/water $(2 \mathrm{v} / 1 \mathrm{v})$ and heated at $100^{\circ} \mathrm{C}$. After cooling, the organic phase 
was separated and washed twice with aqueous $\mathrm{HCl}(2 \mathrm{M})$, twice with water then saturated aqueous sodium hydrogen carbonate solution. The presence of chlorin and bacteriochlorin in the solution was controlled by UV-visible spectroscopy (bands at 651 and $738 \mathrm{~nm}$, respectively). $o$-Chloranil (2.5 eq.) was slowly added to the stirred organic solution at room temperature until the absorption peak of bacteriochlorin species disappeared. The solution was washed with aqueous solution of $\mathrm{NaHSO}_{3}(5 \%)$, water and dried over sodium sulfate. The filtered solution was concentrated under vacuum. The crude product was purified by crystallization. The chlorin was obtained as mauve/green powder.

5,15-diphenyl-2,3-chlorin : 6a The compound 6a was prepared from 5,15-diphenylporphyrin 5a (583 mg, $1.26 \mathrm{mmol})$. The chlorin 6a after chromatography on silica gel eluted with a mixture of methylene chloride/n-heptane $(1 / 1, \mathrm{v} / \mathrm{v})$, crystallized from a mixture of methylene chloride/n-heptane (543 mg, yield $93 \%$ ). ( $\mathrm{Rf}=0.54, \mathrm{SiO}_{2}, \mathrm{CH}_{2} \mathrm{Cl}_{2} / \mathrm{n}$-heptane, v/v, 1/1). Anal. $\left(\mathrm{C}_{32} \mathrm{H}_{24} \mathrm{~N}_{4}\right), 2 \mathrm{CH}_{2} \mathrm{Cl}_{2}$ calc. $\mathrm{C}$ 64.37, $\mathrm{H}$ 4.45, $\mathrm{N}$ 8.83, found $\mathrm{C}$ 65.61, $\mathrm{H}$ 3.76, $\mathrm{N}$ 8.77. UV-vis spectrum in $\mathrm{CH}_{2} \mathrm{Cl}_{2}: \lambda_{\max }, \mathrm{nm}\left(\varepsilon \mathrm{L}_{\mathrm{mmol}}{ }^{-1} . \mathrm{cm}^{-1}\right): 409$ (99.9), 504,5 (7.2), 531 (3.4), 590 (2.8), 642 (17.9). ${ }^{1} \mathrm{H}$ NMR $\left(\mathrm{CDCl}_{3}\right) \delta$ (ppm) : 9.82 (s, 1H, H-10), 9.08 (d, 1H, J=4.7 Hz, H-8), 8.97 (s, 1H, H-20), 8.94 (d, 1H, J=4.3 Hz, H-12), 8.80 (d, 1H, J=4.7 Hz, H-18), 8.77 (d, 1H, $J=4.7 \mathrm{~Hz}, \mathrm{H}-17), 8.63$ (d, 1H, $J=4.3 \mathrm{~Hz}, \mathrm{H}-13), 8.36$ (d, 1H, $J=4.7 \mathrm{~Hz}, \mathrm{H}-7), 8.15-$ 8.18 (m, 2H, H-o-phenyl), 7.89-7.92 (m, 2H, H-o-phenyl), 7.69-7.76 (m, 6H, H- $m$, p-phenyl), $4.64(\mathrm{~m}, 2 \mathrm{H}, \mathrm{H}-2), 4.32$ (m, 2H, H-3), -1.44 (s, 1H, NH), -1.93 (s, 1H, NH). ${ }^{13} \mathrm{C}$ NMR $\left(\mathrm{CDCl}_{3}\right) \delta(\mathrm{ppm}): 167.7$ (C-4), 167.1 (C-1), 152.4 (C-14), 151.5 (C-11), 142.06 (C-9), 141.2 (C-6), 139.9 (C-19), 135.7 (C-16), 134.2 (C-o-phenyl), 132.39 (C-o-phenyl), 132.19 (C-12), 131.5 (C-13), 128.3 (C-18), 128.2 (C-8), 127.6 (C-m, p-phenyl), 123.9 (C-17), 123.08 (C-7), 121.2 (C-15), 111.9 (C-5), 107.9 (C-10), 97.1 (C-20), 35.7 (C-2), 35.4 (C-3).

5,15-di(4-isopropyloxyphenyl)-2,3-chlorin : 6b The title compound was prepared from 5,15di(4-isopropyloxyphenyl-2,3-porphyrin $\mathbf{5 b}(100 \mathrm{mg}, 0.73 \mathrm{mmol})$. The chlorin $\mathbf{6 b}$ crystallized from a mixture of methylene chloride/methanol $(77 \mathrm{mg}$, yield $77 \%)$. $\left(\mathrm{Rf}=0.41, \mathrm{SiO}_{2}\right.$, $\mathrm{CHCl}_{3} / \mathrm{n}$-heptane, v/v, 1/1). Anal. $\left(\mathrm{C}_{38} \mathrm{H}_{36} \mathrm{~N}_{4} \mathrm{O}_{2}\right), 5 \mathrm{H}_{2} \mathrm{O}$ calc. $\mathrm{C} 68.04, \mathrm{H} 6.91, \mathrm{~N} 8.35$, found $\mathrm{C}$ 67.87, $\mathrm{H}$ 6.58, N 5.89. UV-vis spectrum in $\mathrm{CH}_{2} \mathrm{Cl}_{2}: \lambda_{\max }, \mathrm{nm}\left(\varepsilon \mathrm{L} \cdot \mathrm{mmol}^{-1} . \mathrm{cm}^{-1}\right): 411$ (118.5), 506.5 (7.7), 538 (4.3), 588 (2.9), 643 (14.6). ${ }^{1} \mathrm{H}$ NMR $\left(\mathrm{CDCl}_{3}\right) \delta(\mathrm{ppm}): 9.81(\mathrm{~s}, 1 \mathrm{H}$, H-10), 9.08 (d, 1H, J=4.6 Hz, H-8), 8.98 (s, 1H, H-20), 8.94 (d, 1H, J=4.4 Hz, H-12), 8.84 (d, 1H, $J=4.6 \mathrm{~Hz}, \mathrm{H}-17), 8.77$ (d, 1H, $J=4.6 \mathrm{~Hz}, \mathrm{H}-18), 8.67$ (d, 1H, $J=4.4 \mathrm{~Hz}, \mathrm{H}-13), 8.41$ 
(d, 1H, $J=4.5 \mathrm{~Hz}, \mathrm{H}-7), 8.06$ (d, 2H, $J=8.4 \mathrm{~Hz}, \mathrm{H}-o$-phenyl), 7.76 (d, 2H, $J=8.3 \mathrm{~Hz}, \mathrm{H}-o$ phenyl), 7.34-7.20 (m, 4H, H-m-phenyl), 4.83 [sept., 4H, $J=6 \mathrm{~Hz}, \mathrm{O}-\mathrm{C}_{2}\left(\mathrm{CH}_{3}\right)_{2}$ ], 4.66 (m, $2 \mathrm{H}, \mathrm{H}-2), 4.35$ (m, 2H, H-3), $1.55\left[\mathrm{t}, 12 \mathrm{H}, J=6 \mathrm{~Hz}, \mathrm{O}-\mathrm{CH}_{2}\left(\mathrm{CH}_{3}\right)_{2}\right],-1.93(\mathrm{~s}, 2 \mathrm{H}, \mathrm{NH}) .{ }^{13} \mathrm{C}$ NMR $\left(\mathrm{CDCl}_{3}\right) \delta(\mathrm{ppm}): 167.9$ (C-4), 166.8 (C-1), 158 (C-p-phenyl), 153.5 (C-14), 150 (C11), 141 (C-6), 140 (C-19), 136 (C-16), 135.2 (C-o-phenyl), 134 (C-phenyl, C-9), 133 (C-ophenyl), 132.5 (C-12), 131.7 (C-13), 128.2 (C-17), 127.9 (C-8), 123.5 (C-18), 123 (C-7), 121.5 (C-15), 115 (C-m-phenyl), 114 (C-m-phenyl), 111.3 (C-5), 108 (C-10), 96.9 (C-20), $70.2(\mathrm{O}-\mathrm{CH}), 35.5(\mathrm{C}-2, \mathrm{C}-3), 22.4\left(\mathrm{CH}_{3}\right)$.

\section{0-bromo-5,15-diphenyl-2,3-chlorin : 7a and 12,20-dibromo-5,15-diphenyl-2,3-chlorin : 8a}

The 5,10-diphenyl chlorin 6a (100 mg, $0.215 \mathrm{mmol})$ was dissolved in methylene chloride (30 $\mathrm{mL})$ then N-bromo-succinimide (NBS), $(38 \mathrm{mg}, 0.215 \mathrm{mmol})$ was added. The disappearance of initial product was controlled by analytical thin layer chromatography $\left(\mathrm{SiO}_{2}\right.$, eluted by a mixture of $\mathrm{n}$-heptane/methylene chloride, 7/3, v/v). After one hour, the solution was concentrated under vacuum. The crude material was washed with hot methanol $(185 \mathrm{~mL})$. The crystallized crude product was dried under vacuum (over night, $0.5 \mathrm{~mm} \mathrm{Hg}$ ). The two compounds were purified by preparative silica gel thin layer chromatography eluted by a mixture of methylene chloride/n-heptane, 7/3, v/v. The 20-bromo-5,15-diphenyl-2,3-chlorin $\left(\mathrm{Rf}=0.35, \mathrm{SiO}_{2}, \mathrm{CH}_{2} \mathrm{Cl}_{2} / \mathrm{n}\right.$-heptane, v/v, 7/3, $30 \mathrm{mg}$, yield $26 \%$ ) and the 12,20-dibromo5,15-diphenyl-2,3-chlorin ( $\mathrm{Rf}=0.47, \mathrm{SiO}_{2}, \mathrm{CH}_{2} \mathrm{Cl}_{2} / \mathrm{n}$-heptane, v/v, 7/3, $27 \mathrm{mg}, 20 \%$ ) were obtained as purple powders.

20-bromo-5,15-diphenyl-2,3-chlorin : 7a Anal. $\left(\mathrm{C}_{32} \mathrm{H}_{23} \mathrm{BrN}_{4}\right), \mathrm{CH}_{2} \mathrm{Cl}_{2}, 2 \mathrm{C}_{7} \mathrm{H}_{16}$, Calc. $\mathrm{C}$ 66.84, H 6.39, $\mathrm{N} 7.25$, found. C 66.11, H 5.92, $\mathrm{N}$ 6.85. UV-vis spectrum in $\mathrm{CH}_{2} \mathrm{Cl}_{2}: \lambda_{\text {max }}$, $\mathrm{nm}\left(\varepsilon \mathrm{L} . \mathrm{mmol}^{-1} \cdot \mathrm{cm}^{-1}\right)$ : 412 (188.5), 514 (13.2), 542 (9.2), 595 (5.8), 648 (33.4). ${ }^{1} \mathrm{H}$ NMR $\left(\mathrm{CDCl}_{3}\right) \delta(\mathrm{ppm}): 9.67$ (s, 1H, H-10), 9.17 (d, 1H, J=4.9 Hz, H-8), 8.99 (d, 1H, J = 4.8 Hz, H-18), 8.83 (d, 1H, $J=4.4$ Hz, H-12), 8.70 (d, 1H, $J=4.9$ Hz, H-7), 8.56 (d, 1H, $J=4.4$ Hz, H-13), 8.28 (d, 1H, $J=4.7 \mathrm{~Hz}, \mathrm{H}-17), 8.12$ (m, 2H, H- $o$-phenyl), 7.82 (m, 2H, H- $o^{\prime}$-phenyl), 7.71 (m, 9H, H-m, p'-phenyl), 4.62 (m, 2H, H-12), 4.21 (m, 2H, H-3), -1.60 (s, 1H, NH)-1.90 (s, 1H, NH). ${ }^{13} \mathrm{C}$ NMR $\left(\mathrm{CDCl}_{3}\right) \delta(\mathrm{ppm}): 169.20$ (C-4), 166.33 (C-1), 152.43 (C-14, C-11), 141.82 (C-1 phenyl), 141.43 (C-1 phenyl), 141.01 (C-16), 138.10 (C-9), 135.55 (C-6 or C19), 135.37 (C-19 or C-6), 133.95 (C-o-phenyl), 133.03 (C-13), 132.33 (C-12), 132.26 (C-o'- 
phenyl), 128.42 (C-18), 128.30 (C-7), 128.14 (C-p-phenyl), 126.83 (C-m-phenyl), 124.41 (C17, C-8), 123.54 (C-15), 112.20 (C-5), 107.39 (C-10), 96.94 (C-20), 39.06 (C-2), 35.98 (C-3).

12,20-dibromo-5,15-diphenyl-2,3-chlorin : 8a Anal. $\left(\mathrm{C}_{32} \mathrm{H}_{22} \mathrm{~N}_{4} \mathrm{O}_{4}\right), \mathrm{CH}_{2} \mathrm{Cl}_{2}, 2 \mathrm{C}_{7} \mathrm{H}_{16}$, Calc. C 60.65, H 5.68, N 6.58, found C 62.45, $\mathrm{H}$ 5.44, $\mathrm{N}$ 6.56. UV-vis spectrum in $\mathrm{CH}_{2} \mathrm{Cl}_{2}: \lambda_{\text {max }}$, $\mathrm{nm}\left(\varepsilon \mathrm{L} . \mathrm{mmol}^{-1} . \mathrm{cm}^{-1}\right): 412$ (188.5), 518 (10.7), 545 (6.8), 595 (4.8), 648 (25.9). ${ }^{1} \mathrm{H}$ NMR $\left(\mathrm{CDCl}_{3}\right) \delta(\mathrm{ppm}): 9.84$ (s, 1H, H-10), $9.13(\mathrm{~d}, 1 \mathrm{H}, J=4.8 \mathrm{~Hz}, \mathrm{H}-18), 9.04$ (d, 1H, $J=4.8 \mathrm{~Hz}$, H-8), 8.67 (d, 1H, J=4.5 Hz, H-17), 8.53 (s, 1H, H-13), 8.28 (d, 1H, J=4.8 Hz, H-7), 8.06 (m, 2H, H-o-phenyl), 7.83 (m, 2H, H-o'-phenyl), 7.71 (m, 6H, H-m, p-phenyl), 4.60 (m, 2H, $\mathrm{H}-2), 4.20$ (m, 2H, H-3), -1.64 (s 1H, NH), -1.90 (s, $1 \mathrm{H}, \mathrm{NH}) .{ }^{13} \mathrm{C} \mathrm{NMR}\left(\mathrm{CDCl}_{3}\right) \delta$ (ppm) : 169.91 (C-4), 167.01 (C-1), 150.20 (C-14 or C-11), 148.28 (C-11 or C-14), 141.82 (C-1, phenyl), 141.43 (C-1, phenyl), 140.86 (C-6 or C-9), 138.54 (C-19), 135.72 (C-9 or C-6), 135.22 (C-16), 133.85 (o-phenyl), 132.92 (C-13), 132.20 (o-phenyl), 129.16 (C-8), 128.86 (C-17), 128.22 (p-phenyl), 126.97 (m-phenyl), 124.87 (C-7 or C-18), 124.74 (C-18 or C-7), 123.39 (C-15), 120.72 (C-12), 112.65 (C-5), 104.73 (C-10), 97.20 (C-20), 39.06 (C-2), 36.02 (C-3).

20-bromo-5,15-di(4-isopropyloxyphenyl)-2,3-chlorin : 7a and 12,20-dibromo-5,15-di(4isopropyloxyphenyl)-2,3-chlorin : 8b The 5,10-di(4-isopropyloxyphenyl)chlorin $\mathbf{6 b}$ (100 mg, $0.17 \mathrm{mmol})$ was dissolved in THF $(100 \mathrm{~mL})$ then NBS $(31 \mathrm{mg}, 0.17 \mathrm{mmol})$ was added. The disappearance of initial product was controlled by analytical thin layer chromatography $\left(\mathrm{SiO}_{2}\right.$, eluted by toluene). After one hour, the solution was concentrated under vacuum. The crude material was washed with hot methanol $(185 \mathrm{~mL})$. The crystallized crude product was dried under vacuum (overnight, $0.5 \mathrm{~mm} \mathrm{Hg}$ ). The two compounds were purified by preparative silica gel thin layer chromatography eluted by toluene. The 20-bromo-5,15-di(4isopropyloxyphenyl)-2,3-chlorin $7 \mathbf{b}\left(\mathrm{Rf}=0.67, \mathrm{SiO}_{2}\right.$, toluene, $62 \mathrm{mg}$, yield $\left.44 \%\right)$ and the 12,20-dibromo-5,15-di(4-isopropyloxyphenyl)-2,3-chlorin $\mathbf{8 b}\left(\mathrm{Rf}=0.84, \mathrm{SiO}_{2}\right.$, toluene, 18 $\mathrm{mg}, 12 \%)$ were obtained as purple powders.

20-bromo-5,15-di(4-isopropyloxyphenyl)-2,3-chlorin : 7b UV-vis spectrum in $\mathrm{CH}_{2} \mathrm{Cl}_{2}$ : $\lambda_{\text {max }}, \mathrm{nm}\left(\varepsilon \mathrm{L} . m m o l^{-1} . \mathrm{cm}^{-1}\right)$ : 409.5 (155.7), 515 (11.7), 543.5 (12.1), 596 (5.4), 649 (34.8).

ESI $^{+}$MS calc. for $\mathrm{C}_{38} \mathrm{H}_{35} \mathrm{BrN}_{4} \mathrm{O}_{2},(\mathrm{M}+\mathrm{H})^{+}$659.19, found 659.2. ${ }^{1} \mathrm{H}$ NMR $\left(\mathrm{CDCl}_{3}\right) \delta(\mathrm{ppm})$ : 9.68 (s, 1H, H-10), 9.18 (d, 1H, J=4.6 Hz, H-8), 9.01 (d, 1H, J=4.5 Hz, H-18), 8.85 (d, 1H, 
$J=4.4 \mathrm{~Hz}, \mathrm{H}-12), 8.76$ (d, 1H, $J=4.9 \mathrm{~Hz}, \mathrm{H}-7), 8.62$ (d, 1H, $J=4.3 \mathrm{~Hz}, \mathrm{H}-13), 8.35$ (d, 1H, $J=4.5 \mathrm{~Hz}, \mathrm{H}-17), 8.02$ (d, 2H, $J=8.5 \mathrm{~Hz}, \mathrm{H}-o$-phenyl), 7.75 (d, 2H, $J=8.5 \mathrm{~Hz}, \mathrm{H}-o^{\prime}-$ phenyl), 7.23 (m, 4H, H-m-phenyl), 4.83 [sept, $2 \mathrm{H}, J=6.2 \mathrm{~Hz}, \mathrm{C} \underline{\mathrm{H}}\left(\mathrm{CH}_{3}\right)_{2}$ ], 4.67 (m, 2H, H2), 4.29 (m, 2H, H-3), 1,57 [m, 12H, $\left.\mathrm{CH}\left(\mathrm{CH}_{3}\right)_{2}\right],-1.51$ (s, 1H, NH), -1.84 (s, 1H, NH).

12, 20-dibromo-5,15-di(4-isopropyloxyphenyl)-2,3-chlorin : 8b UV-vis spectrum in $\mathrm{CH}_{2} \mathrm{Cl}_{2}$ : $\lambda_{\text {max }}, \mathrm{nm}\left(\varepsilon\right.$ L.mmol $\left.^{-1} . \mathrm{cm}^{-1}\right): 416$ (181.9), 520 (13.9), 549.5 (11.2), 596 (6.7), 648.5 (35.8). ${ }^{1} \mathrm{H} \mathrm{NMR}\left(\mathrm{CDCl}_{3}\right) \delta$ (ppm) : 9.83 (s, 1H, H-10), 9.15 (d, 1H, J=4.3 Hz, H-18), 9.05 (d, 1H, $J$ $=4.5 \mathrm{~Hz}, \mathrm{H}-8), 8.74$ (d, 1H, J=3.7 Hz, H-17), 8.60 (s, 1H, H-13), 8.35 (d, 1H, J=3.5 Hz, H7), 7.97 (d, 2H, $J=8.5 \mathrm{~Hz}, \mathrm{H}-o$-phenyl), 7.72 (d, 2H, $J=8.5 \mathrm{~Hz}, \mathrm{H}-o^{\prime}$-phenyl), 7.22 (m, 4H, H-m-phenyls), 4.82 [sept, 2H, $\left.J=6.2 \mathrm{~Hz}, \mathrm{C} \underline{\mathrm{H}}\left(\mathrm{CH}_{3}\right)_{2}\right], 4.63$ (m, 2H, H-2), 4.26 (m, 2H, H-3), $1,56\left[\mathrm{~m}, 12 \mathrm{H}, \mathrm{CH}\left(\mathrm{CH}_{3}\right)_{2}\right],-1.55(\mathrm{~s}, 1 \mathrm{H}, \mathrm{NH}),-1.81(\mathrm{~s} 1 \mathrm{H}, \mathrm{NH})$.

\section{5,10,20-triphenyl-2,3-chlorin :9a}

1) By Suzuki's reaction : 20-Bromo-5,15-diphenyl-2,3-chlorin 7a (32 mg, $0.06 \mathrm{mmol})$ were dissolved in freshly distilled dimethylformamide $(15 \mathrm{~mL})$ and kept under argon during 1 hour. $\mathrm{Pd}\left(\mathrm{PPh}_{3}\right)_{4}(20.5 \mathrm{mg}, 0.02 \mathrm{mmol})$, phenylboronic acid $(36 \mathrm{mg}, 0.3 \mathrm{mmol})$ and aqueous sodium carbonate $(236 \mu \mathrm{L}, 0.5 \mathrm{mMol})$ were added. The crude solution was refluxed for 3 hours. The solution was concentrated under vacuum. The crude product was purified by silica gel column chromatography $\left(\mathrm{Rf}=0.35, \mathrm{CH}_{2} \mathrm{Cl}_{2} /\right.$ cyclohexane, $\left.1 / 1, \mathrm{v} / \mathrm{v}\right)$ and crystallized from a mixture of $\mathrm{CH}_{2} \mathrm{Cl}_{2}$-heptane. Titled compound was obtained as mauve/green powder (14 mg, yield $44 \%$ ).

2) By modified Bonnett's method : The 5,10,15-triphenyl porphyrin 10 (50 mg, $9.210^{-5}$ $\mathrm{mol}$ ) and anhydrous potassium carbonate (384 mg, $2.78 \mathrm{mmol}, 30$ eq.) were dissolved in dry pyridine (4.5 mL). $p$-Toluenesulfonhydrazide (345 mg, $1.85 \mathrm{mmol}, 20$ eq.) in dry pyridine (1 $\mathrm{mL}$ ) was added. The mixture was heated at $100-105^{\circ} \mathrm{C}$ under argon for 24 hours. Further quantities of $p$-toluenesulfonhydrazide (35 mg, 2 eq. in $1 \mathrm{~mL}$ of dry pyridine) were added after 2, 4, 6 and 8 hours. After cooling, the mixture was treated with a mixture of ethyl acetate/water $(45 \mathrm{~mL}, 2 / 1, \mathrm{v} / \mathrm{v})$ and heated at $100^{\circ} \mathrm{C}$. After cooling, the organic phase was separated and washed twice with aqueous $\mathrm{HCl}(2 \mathrm{M})$, twice with water then saturated aqueous sodium hydrogen carbonate solution. The presence of bacteriochlorin was controlled by UVvisible spectroscopy (band at $738 \mathrm{~nm}$ ). $o$-Chloranil $(57 \mathrm{mg}, 2.5$ eq.) was slowly added to the stirred organic solution at room temperature until the absorption peak of bacteriochlorin species disappeared. The solution was washed with aqueous solution of $\mathrm{NaHSO}_{3}(5 \%)$, water 
and dried over sodium sulfate. The filtered solution was concentrated under vacuum. The crude product was purified by crystallization from a mixture of methylene chloride/heptane. The chlorin was obtained as mauve/green powder (30 mg, yield $60 \%$ ). Anal. $\left(\mathrm{C}_{38} \mathrm{H}_{28} \mathrm{~N}_{4}\right)$, $\mathrm{H}_{2} \mathrm{O}$ Calc. C 81.70, H 5.41, N 10.03, found C 82.86, H 5.45, N 8.51. UV-vis spectrum in $\mathrm{CH}_{2} \mathrm{Cl}_{2}: \lambda_{\max }, \mathrm{nm}\left(\varepsilon \mathrm{L} . \mathrm{mmol}^{-1} \cdot \mathrm{cm}^{-1}\right): 412$ (99.4), 510 (7.6), 537 (4.1), 595 (2.8), 647 (18.7). ${ }^{1} \mathrm{H} \mathrm{NMR}\left(\mathrm{CDCl}_{3}\right) \delta(\mathrm{ppm}): 9.77$ (s. 1H, H-15), 9.05 (d, 1H, J=6.0 Hz, H-17), 8.92 (d, 1H, $J$ $=4.3 \mathrm{~Hz}, \mathrm{H}-13), 8.62$ (d, 1H, $J=4.9 \mathrm{~Hz} . \mathrm{H}-8), 8.59$ (d, 1H, $J=4.3 \mathrm{~Hz}, \mathrm{H}-12), 8.33$ (d, 1H, $J$ $=6.0 \mathrm{~Hz}, \mathrm{H}-18), 8.18$ (d, 1H, J=4.9 Hz, H-7), 8.13 (m, 2H, H-10, H-o-phenyl), 7.91-7.84 (m, 4H, H-5, 20, H-o'-phenyl), 7.72-7.64 (m, 9H, H-5, 10, 20, H-m, p-phenyl), 4.18 (s, 4H, H-2, 3), -1.55 (broad s, 1H, NH), -1.86 (broad s, 1H, NH). ${ }^{13} \mathrm{C} \mathrm{NMR}\left(\mathrm{CDCl}_{3}\right) \delta(\mathrm{ppm}): 167.61-$ 166.53 (C-1, 4), 152.71 (C-11), 151.42 (C-14), 143.49-142.48 (C-1-phenyl), 141.66 (C-1phenyl), 140.69 (C-19), 140.11 (C-6), 135.33 (C-9), 134.68 (C-16), 133.99 (C-o-phenyl), 132.32-131.90 (C-p-phenyl, C-m-phenyl, C-12, 13), 128.57-126.76 (C-m-phenyl, C-8, 17), 123.61-123.50 (C-7, 18), 122.19 (C-10), 112.42-111.90 (C-5, 20), 107.44 (C-15), 36.2-35.7 $(\mathrm{C}-2,3)$.

\section{5,10,20-tri(4-isopropyloxyphenyl)-2,3-chlorin : 9b}

1) By Suzuki's reaction : 20-Bromo-5,15-di(4-isopropyloxyphenyl)-2,3-chlorin $7 \mathbf{b}$ (61 mg, $0.082 \mathrm{mmol})$ were dissolved in a mixture of dioxane/water $(6 \mathrm{~mL} / 1 \mathrm{~mL})$ and kept under argon during 1 hour. $\mathrm{Pd}\left(\mathrm{PPh}_{3}\right)_{4}(10 \mathrm{mg}, 0.008 \mathrm{mmol})$, 4-isopropoxyphenylboronic acid (144 mg, 0.8 mmol) and aqueous sodium carbonate $(140 \mathrm{mg}, 1 \mathrm{mmol})$ were added. The crude solution was heated at $100^{\circ} \mathrm{C}$ for 1 hours. The solution was concentrated under vacuum. The crude product was purified by silica gel column chromatography $(\mathrm{Rf}=0.25$, toluene $)$ and crystallized from a mixture of $\mathrm{CH}_{2} \mathrm{Cl}_{2}$-methanol. Titled compound was obtained as mauve/green powder (43 mg, yield $62 \%$ ).

2) By modified Bonnett's method : The 5,10,15-tri-(5-isopropyloxyphenyl)porphyrin 13 (50 $\mathrm{mg}, 710^{-5} \mathrm{~mol}$ ) and anhydrous potassium carbonate (485 $\mathrm{mg}, 2.78 \mathrm{mmol}, 40$ eq.) were dissolved in dry pyridine (4.5 mL). p-Toluenesulfonhydrazide (263 mg, $1.4 \mathrm{mmol}, 20$ eq.) in dry pyridine $(1 \mathrm{~mL})$ was added. The mixture was heated at $100-105^{\circ} \mathrm{C}$ under argon for 24 hours. Further quantities of $p$-toluenesulfonhydrazide ( $40 \mathrm{mg}, 5$ eq. in $1 \mathrm{~mL}$ of dry pyridine) were added after 2, 4, 6 and 8 hours. After cooling, the mixture was treated with a mixture of chloroform/water $(45 \mathrm{~mL}, 2 \mathrm{v} / 1 \mathrm{v})$ and heated at $100^{\circ} \mathrm{C}$. After cooling, the organic phase was separated and washed twice with aqueous $\mathrm{HCl}(2 \mathrm{M})$, twice with water then saturated aqueous 
sodium hydrogen carbonate solution. The presence of bacteriochlorin was controlled by UVvisible spectroscopy (band at $738 \mathrm{~nm}) . O$-chloranil $(25 \mathrm{mg}, 1.2 \mathrm{eq}$.) was slowly added to the stirred organic solution at room temperature until the absorption peak of bacteriochlorin species disappeared. The solution was washed with aqueous solution of $\mathrm{NaHSO}_{3}(5 \%)$, water and dried over sodium sulfate. The filtered solution was concentrated under vacuum. The crude product was purified by crystallization (methylene chloride/heptane). The chlorin was obtained as mauve/green powder (30 mg, yield $60 \%)$. Anal. $\left(\mathrm{C}_{47} \mathrm{H}_{46} \mathrm{~N}_{4} \mathrm{O}_{3}\right), \mathrm{H}_{2} \mathrm{O}$ calc. $\mathrm{C}$ 77.02, $\mathrm{H}$ 6.60, $\mathrm{N}$ 7.64, found $\mathrm{C} 76.11, \mathrm{H}$ 6.38, $\mathrm{N}$ 7.39. UV-vis spectrum in $\mathrm{CH}_{2} \mathrm{Cl}_{2}: \lambda_{\max }$, $\mathrm{nm}\left(\varepsilon\right.$ L.mmol $\left.{ }^{-1} . \mathrm{cm}^{-1}\right): 416$ (183.1), 513.5 (13.2), 542 (9.4), 595 (5.3), 648 (33.2). ${ }^{1} \mathrm{H}$ NMR $\left(\mathrm{CDCl}_{3}\right) \delta(\mathrm{ppm}): 9.73(\mathrm{~s}, 1 \mathrm{H}, \mathrm{H}-15), 9.04(\mathrm{~d}, 1 \mathrm{H}, J=4.7 \mathrm{~Hz}, \mathrm{H}-17), 8.89$ (d, 1H, $J=4.3 \mathrm{~Hz}$, H-13), 8.66 (d, 1H, $J=4.8 \mathrm{~Hz}, \mathrm{H}-8), 8.62$ (d, 1H, $J=4.3 \mathrm{~Hz}, \mathrm{H}-12), 8.37$ (d, 1H, $J=4.7 \mathrm{~Hz}$, H-18), 8.22 (d, 1H, $J=4.8 \mathrm{~Hz}, \mathrm{H}-7), 8.01$ (d, 2H, $J=8.5 \mathrm{~Hz}, \mathrm{H}-10, \mathrm{H}-o$-phenoxy), 7.72 (m, 4H, H-5, 20, H-o'-phenoxy), 7.18 (d, 2H, $J=8.5$ Hz, H-10, H-m-phenoxy), 7.12 (m, 4H, H-5, 20, H-m-phenoxy), 4.80 [m, 3H, -O-Cㅍ- $\left.\left(\mathrm{CH}_{3}\right)_{2}\right], 4.18$ (s, 4H, H- 2, 3), 1.53 [m, 18H, -O-CH$\left.\left(\mathrm{CH}_{3}\right)_{2}\right],-1.56$ (broad s, $\left.1 \mathrm{H}, \mathrm{NH}\right),-1.87$ (broad s, $\left.1 \mathrm{H}, \mathrm{NH}\right) .{ }^{13} \mathrm{C} \mathrm{NMR}\left(\mathrm{CDCl}_{3}\right) \delta(\mathrm{ppm})$ : 168.03-166.93 (C-1, 4), 157.6 (p-phenoxy), 153.06 (C-11), 151.28 (C-14), 141.25 (C-19), 140.42 (C-6), 135.60-133.90 (C-m-phenoxy, C-o-phenoxy, C-9, C-16), 132.40 (C-12, C-13), 128.18-127.50 (C-17, C-8), 122.97 (C-7, C-18), 122.05 (C-10), 115.93-114.12 (C-mphenoxy), 111.9 (C-5, C-20), 106.33 (C-15), 70.91-69.11 [O- $\left.\underline{\mathrm{C}} \mathrm{H}-\left(\mathrm{CH}_{3}\right)_{2}\right], 35.9$ (C-2, C-3), 23.04-21.54 [CH- $\left.\left(\mathrm{CH}_{3}\right)_{2}\right]$.

12-iodo-5,15-diphenyl-2,3-chlorin : 5,15-diphenylchlorin 6a (46 mg, $0.1 \mathrm{mmol})$ and iodine (38.7 $\mathrm{mg}, \quad 0.15 \mathrm{mmol})$ were dissolved in chloroform $(50 \mathrm{~mL})$. A solution of [bis(fluoroacetoxy)iodo]benzene $(15.4 \mathrm{mg}, 0.036 \mathrm{mmol})$ in chloroform $(0.5 \mathrm{~mL})$ was added slowly. The end of the reaction was checked by thin layer chromatography (chloroform/cyclohexane, 1/1, v/v). After $15 \mathrm{~min}$, the solution was washed with water $(3 \mathrm{x})$, dried over sodium sulfate, filtered and concentrated under vacuum. The crude product was purified by silica gel chromatography $\left(\mathrm{Rf}=0.72, \mathrm{SiO}_{2}\right.$, chloroform/cyclohexane, 1/1, v/v). The iodochlorin was obtained as mauve/green powder (19 mg, yield $35 \%)$. UV-vis spectrum in $\mathrm{CH}_{2} \mathrm{Cl}_{2}$, trace of triethylamine : $\lambda_{\max }, \mathrm{nm}: 416$ (1), 512 (0.08), 542 (shoulder), 589.5 (0.037), 648 (0.178). ESI ${ }^{+}$MS calc. for $\mathrm{C}_{32} \mathrm{H}_{23} \mathrm{IN}_{4},(\mathrm{M}+\mathrm{H})^{+}$591.10, found 591.16. ${ }^{1} \mathrm{H} \mathrm{NMR}$ $\left(\mathrm{CDCl}_{3}\right) \delta(\mathrm{ppm}): 9.89$ (s, 1H, H-10), 9.12 (dd, 1H, J=4.73, $\left.1.89 \mathrm{~Hz}, \mathrm{H}-8\right), 8.94$ (s, 1H, H20), 8.78 (s, H-13), 8.74 (d, 1H, $J=4.8 \mathrm{~Hz}, \mathrm{H}-18$ ), 8.71 (d, 1H, $J=4.8 \mathrm{~Hz}, \mathrm{H}-17), 8.34$ (dd, $1 \mathrm{H}, J=4.73,3.02, \mathrm{H}-7), 8.10$ (m, 2H, H-o-phenyl), 7.86 (m, 2H, H-o'-phenyl), 7.70 (m, 6H, 
H- $m$, p-phenyl), 4.58 (dd, 2H, $J=4.58,8.08 \mathrm{~Hz}, \mathrm{H}-2), 4.27$ (dd, 2H, $J=4.77,8.03 \mathrm{~Hz}, \mathrm{H}-3$ ), 1.53 (broad s, 1H, NH), $-1.89(\mathrm{~s}, 1 \mathrm{H}, \mathrm{NH})$. 


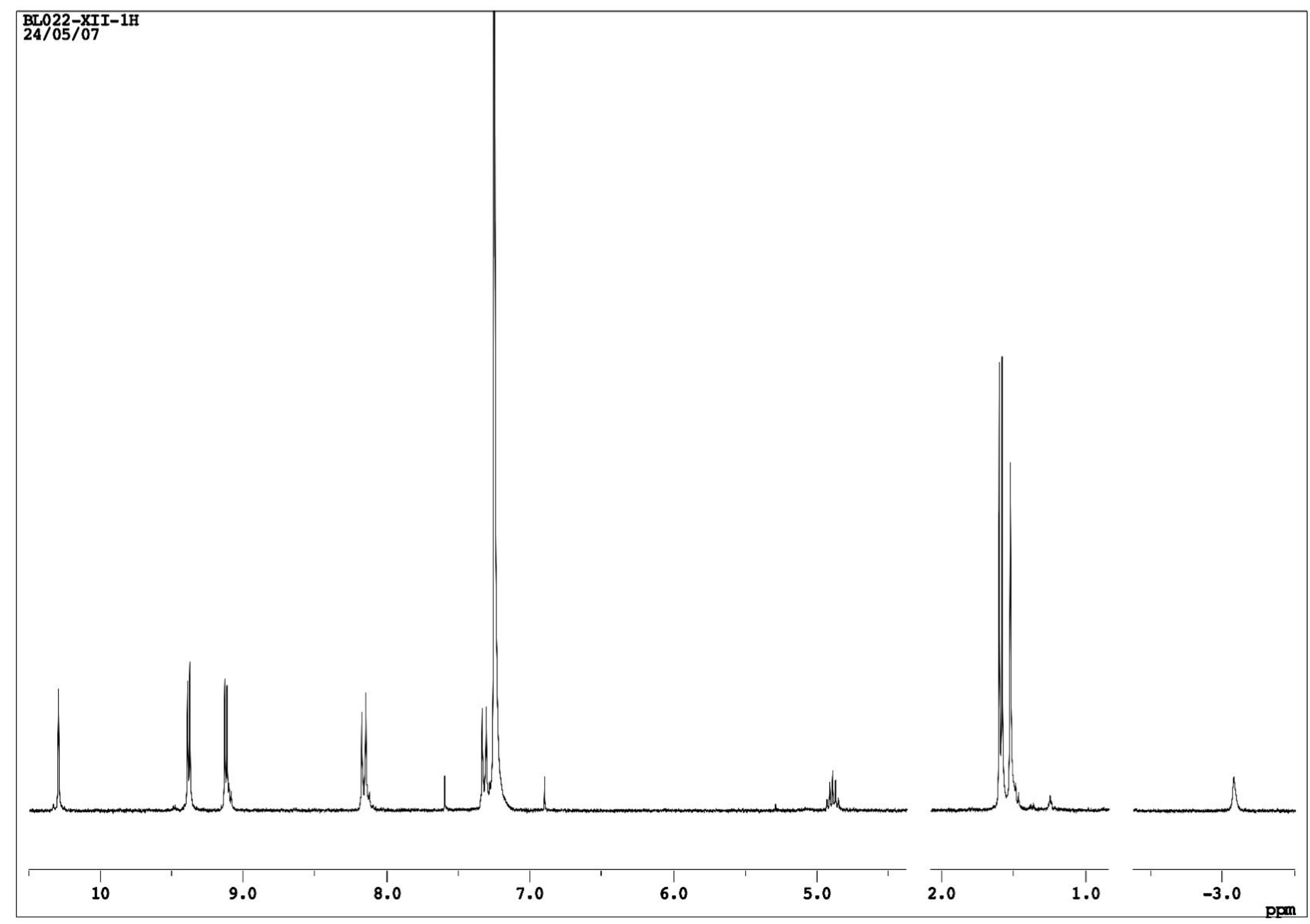

${ }^{1} \mathrm{H}$ NMR spectrum of chlorin $\mathbf{5 b}$ in $\mathrm{CDCl}_{3}$ 


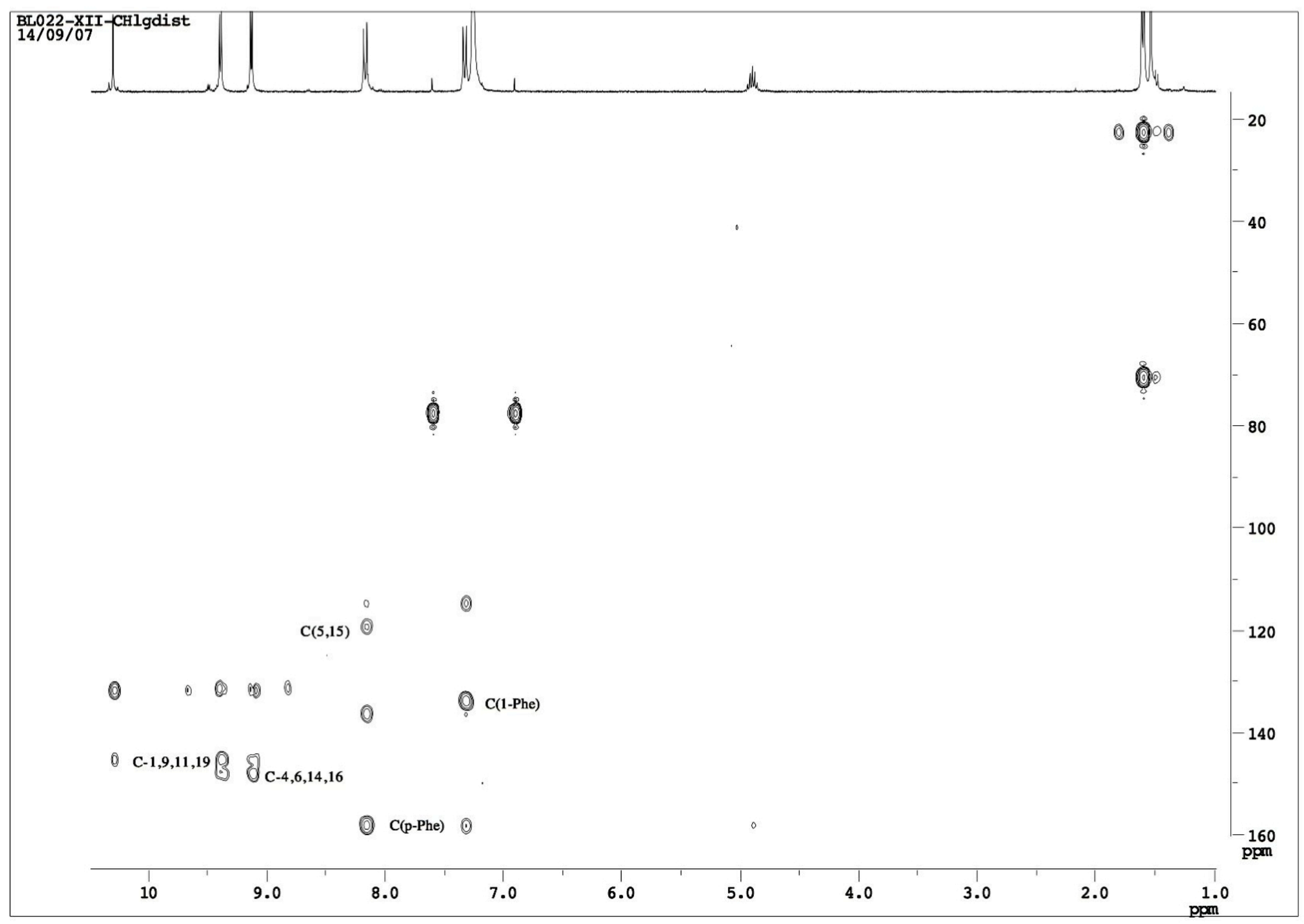

2D NMR spectrum (HMBC) of chlorin $\mathbf{5 b}$ in $\mathrm{CDCl}_{3}$ 


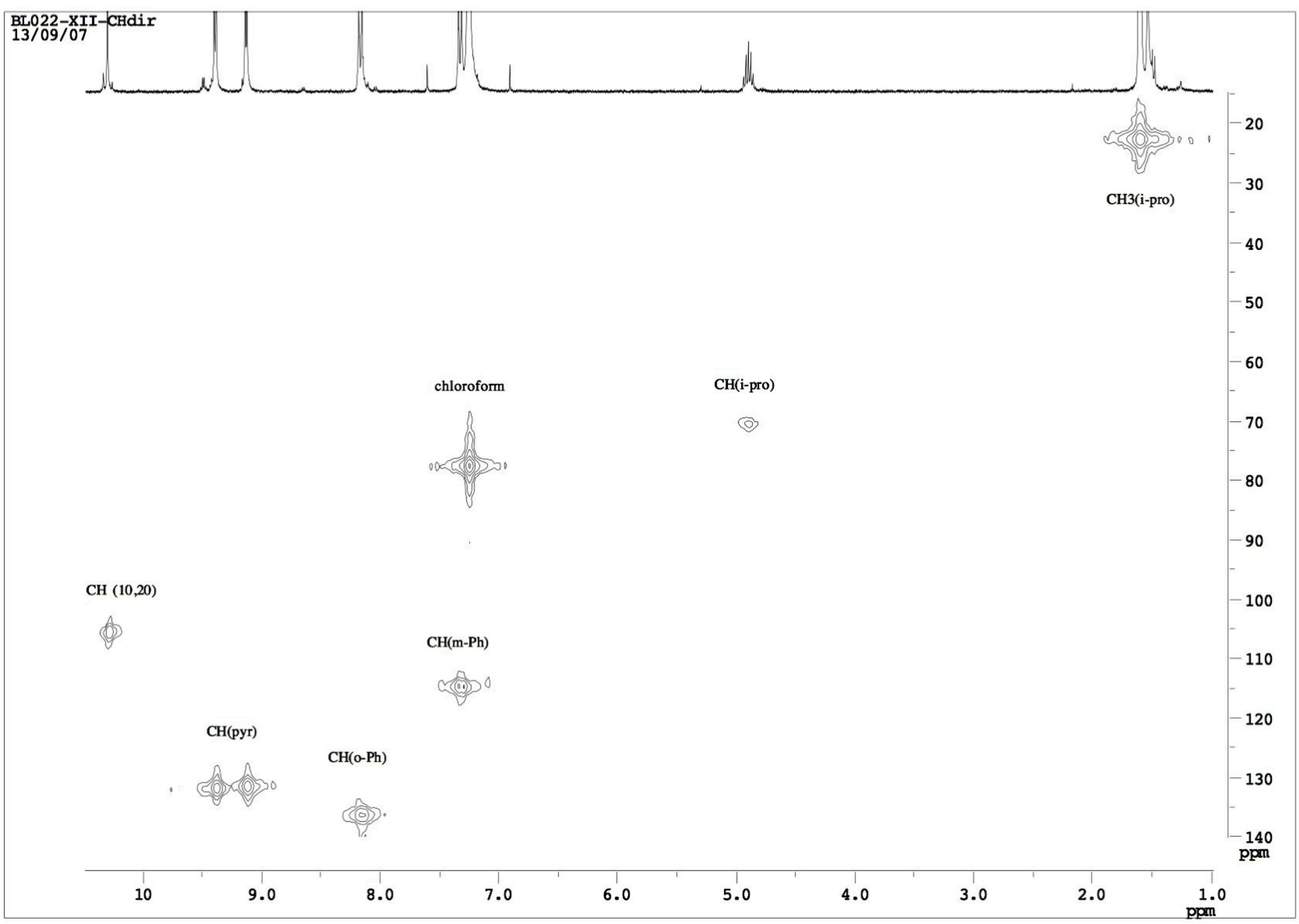

2D NMR spectrum (HMQC) of chlorin $\mathbf{5} \mathbf{b}$ in $\mathrm{CDCl}_{3}$ 


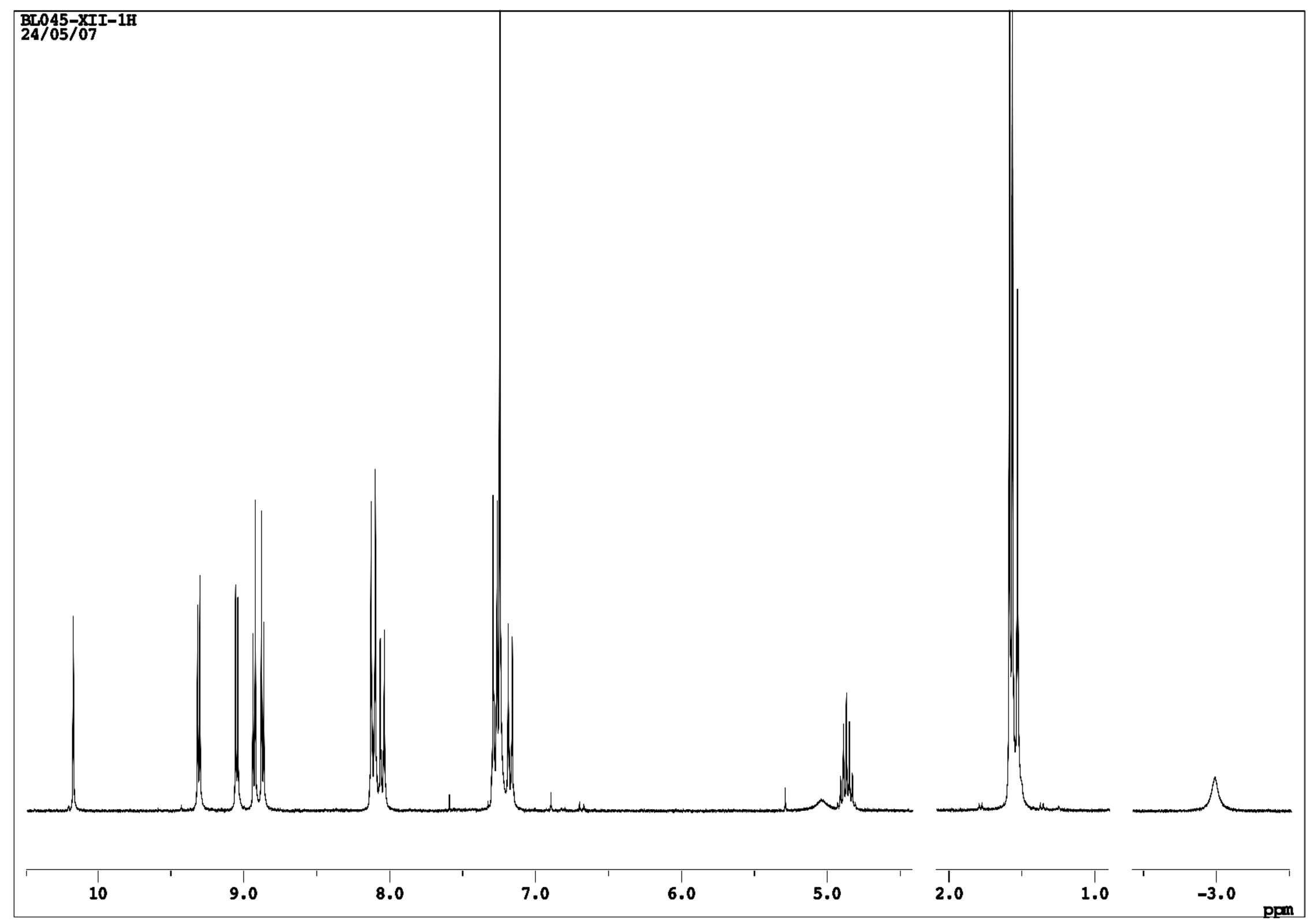

${ }^{1} \mathrm{H}$ NMR spectrum of 5,15-di(p-iso-propyloxyphenyl)-10-( $p$-hydroxyphenyl)porphyrin in $\mathrm{CDCl}_{3}$ 


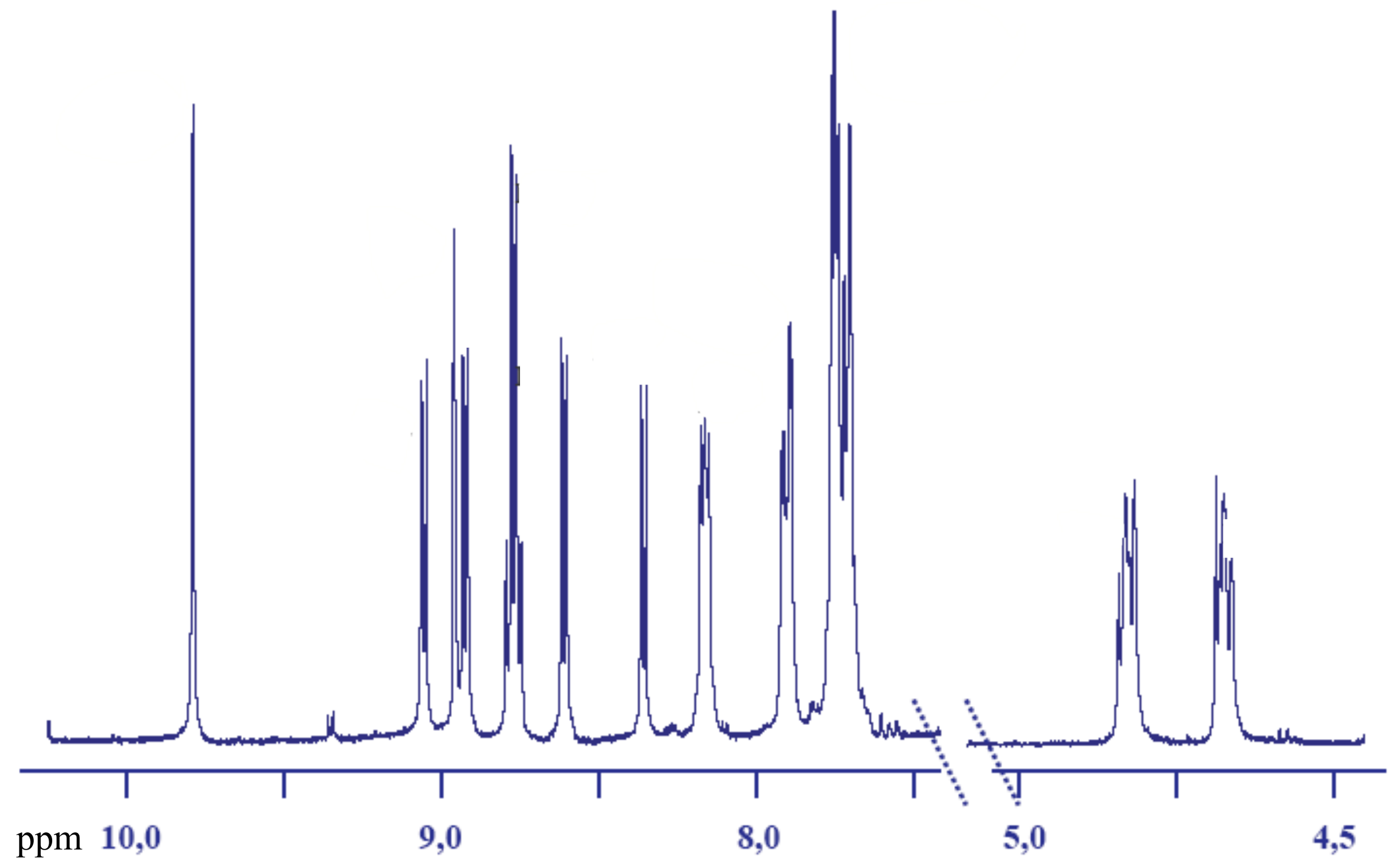

${ }^{1} \mathrm{H}$ NMR spectrum of chlorine $\mathbf{6 a}$ in $\mathrm{CDCl}_{3}$ 


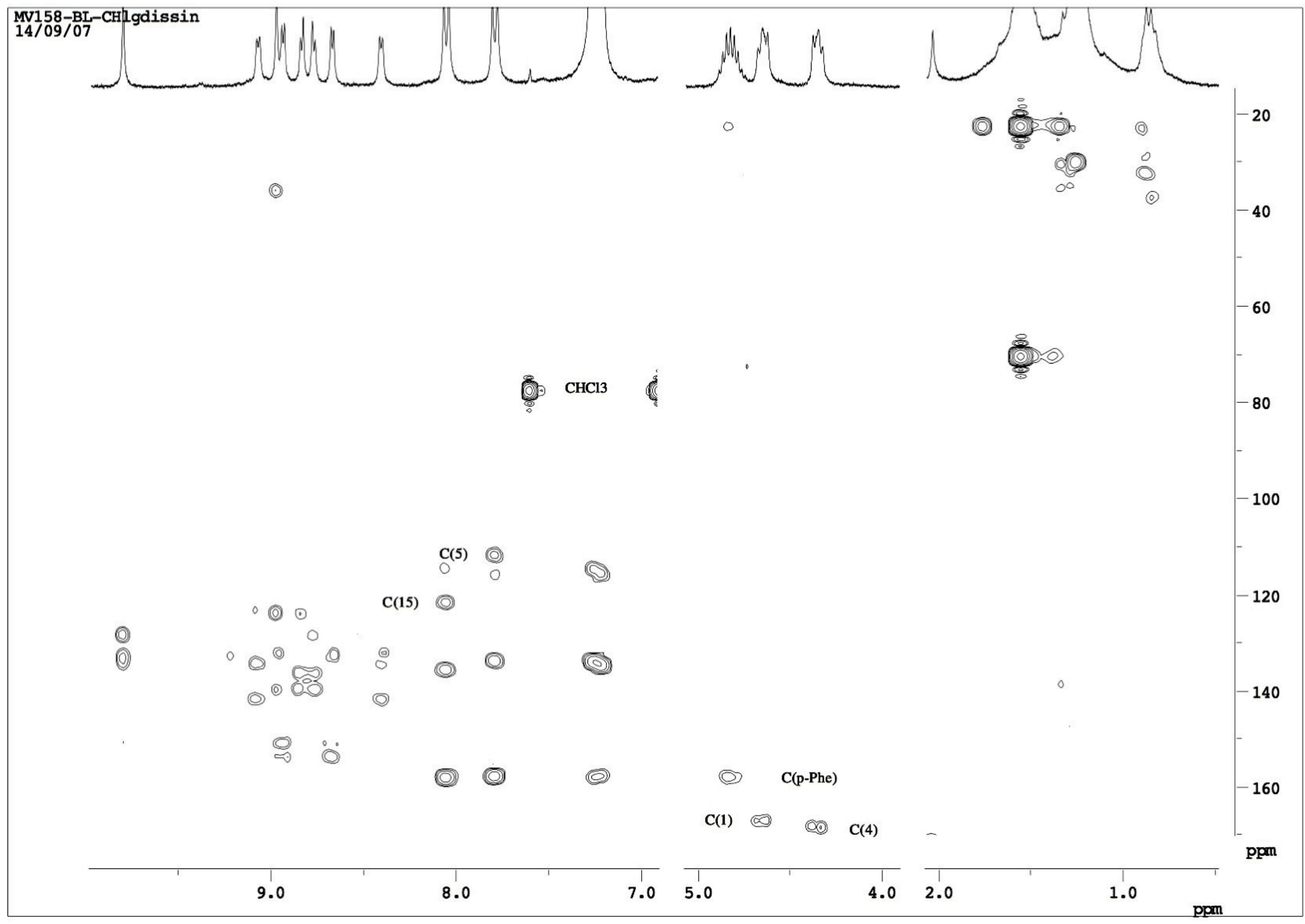

2D NMR spectrum (HMBC) of chlorin $\mathbf{6 a}$ in $\mathrm{CDCl}_{3}$ 


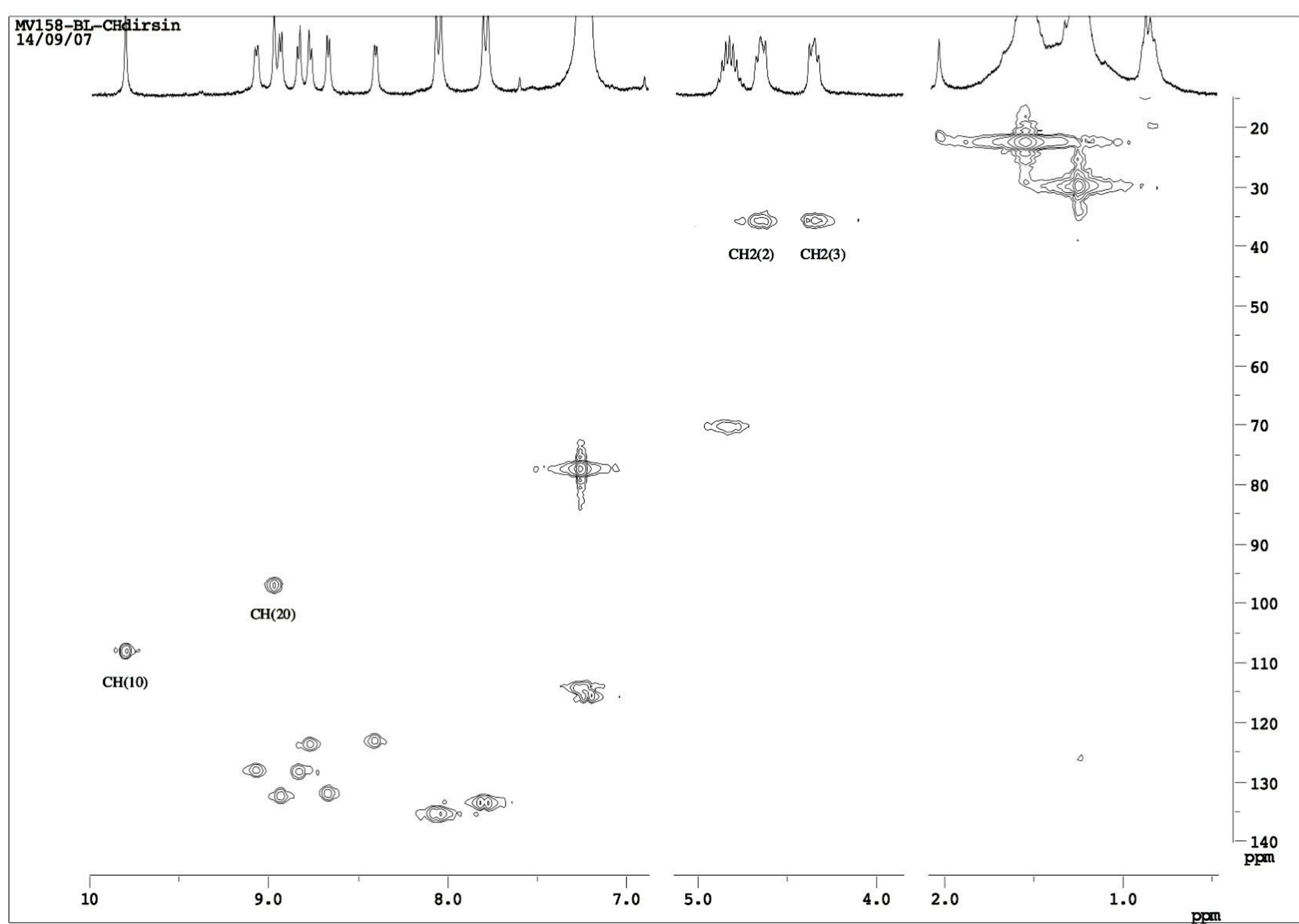

2D NMR spectrum (HMQC) of chlorin $\mathbf{6 a}$ in $\mathrm{CDCl}_{3}$ 


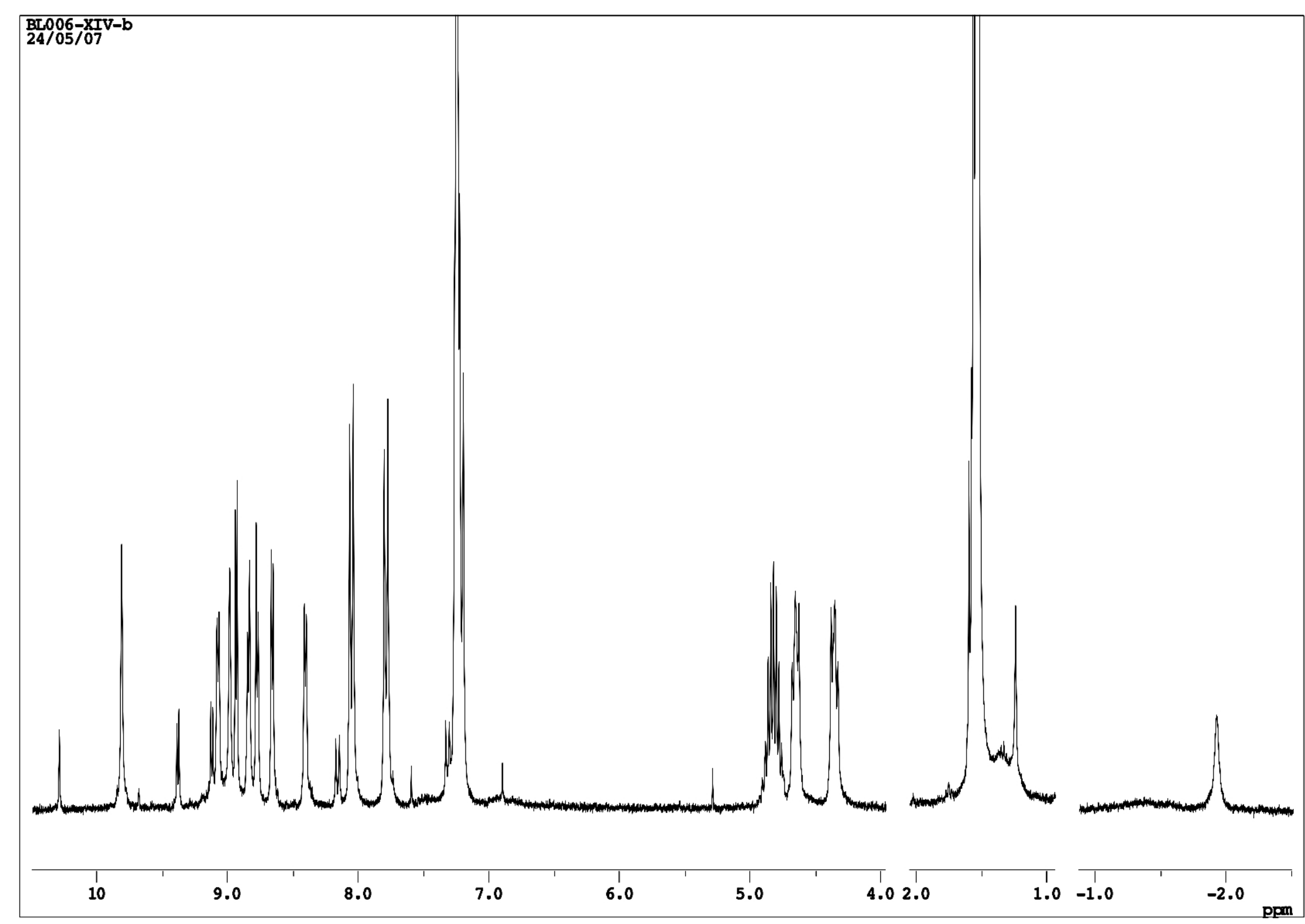

${ }^{1} \mathrm{H}$ NMR spectrum of chlorin $\mathbf{6} \mathbf{b}$ in $\mathrm{CDCl}_{3}$ 


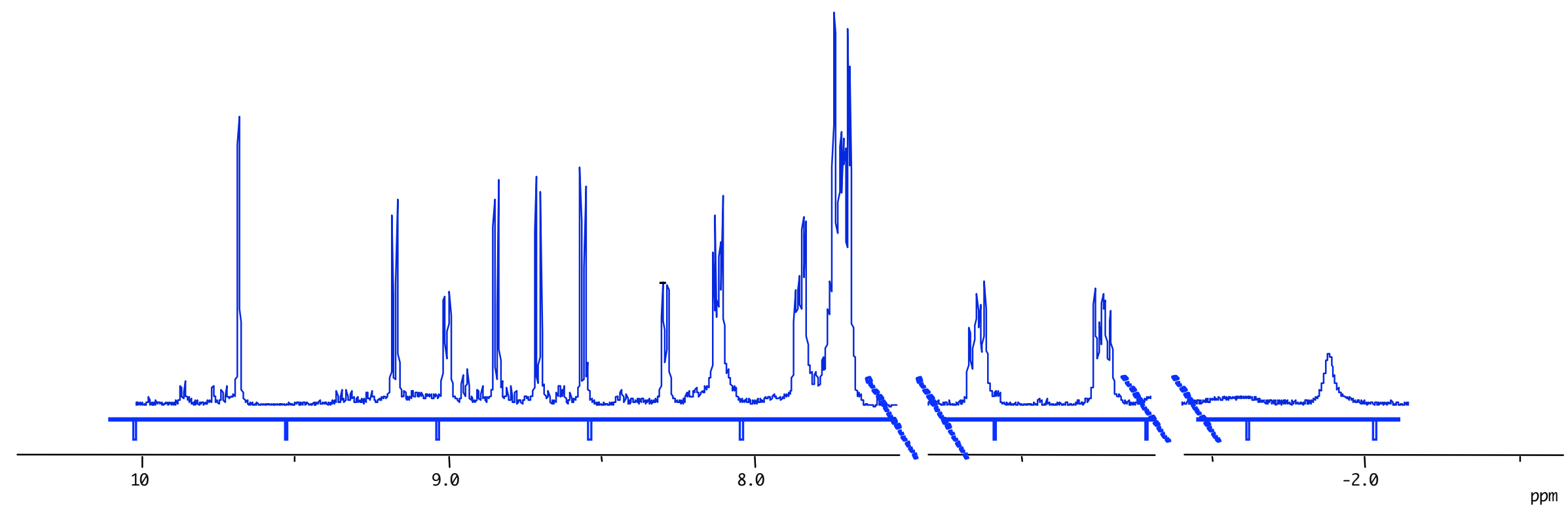

${ }^{1} \mathrm{H}$ NMR spectrum of chlorin $7 \mathbf{a}$ in $\mathrm{CDCl}_{3}$ 


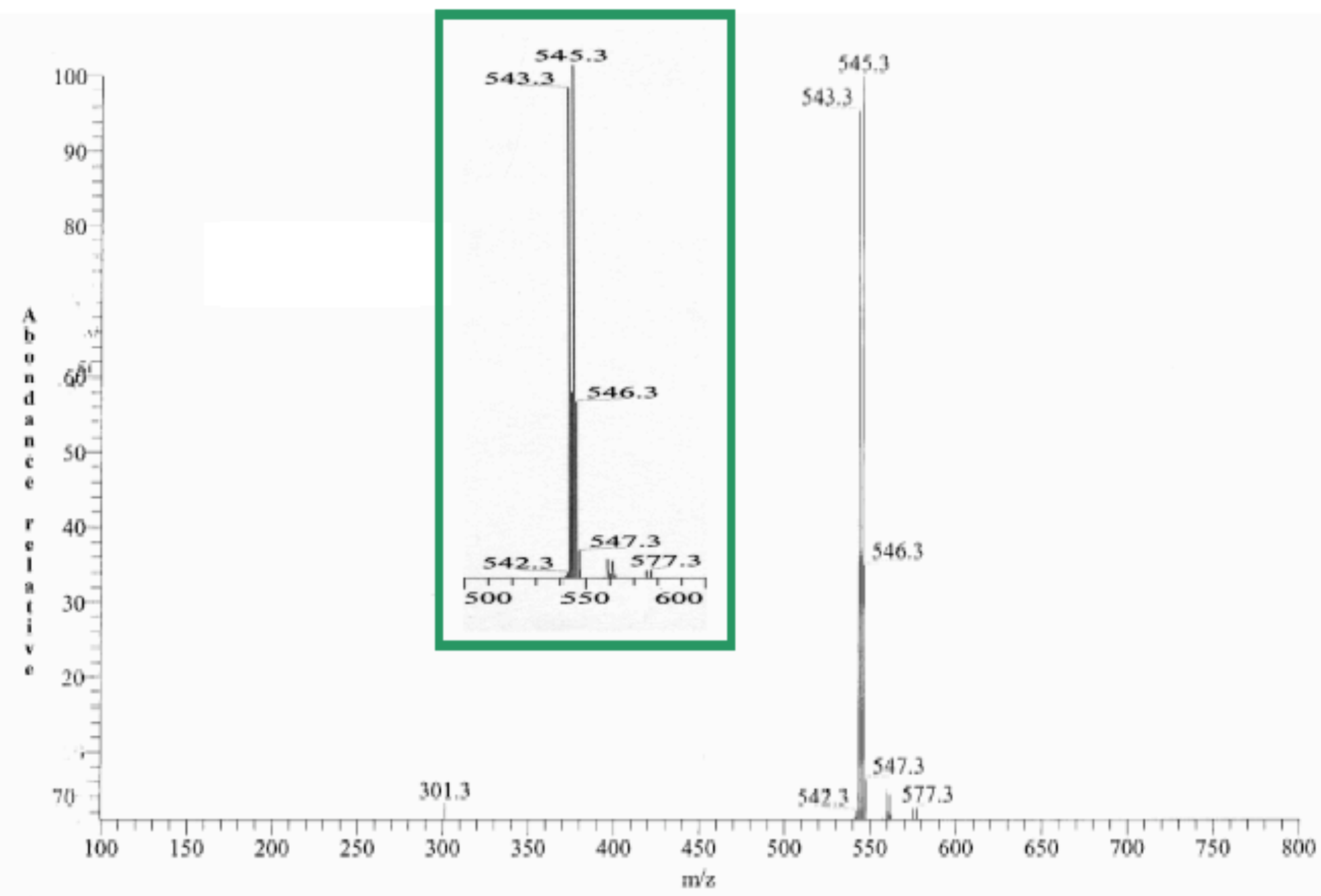

MALDI-TOF mass spectrum of chlorin 7a 


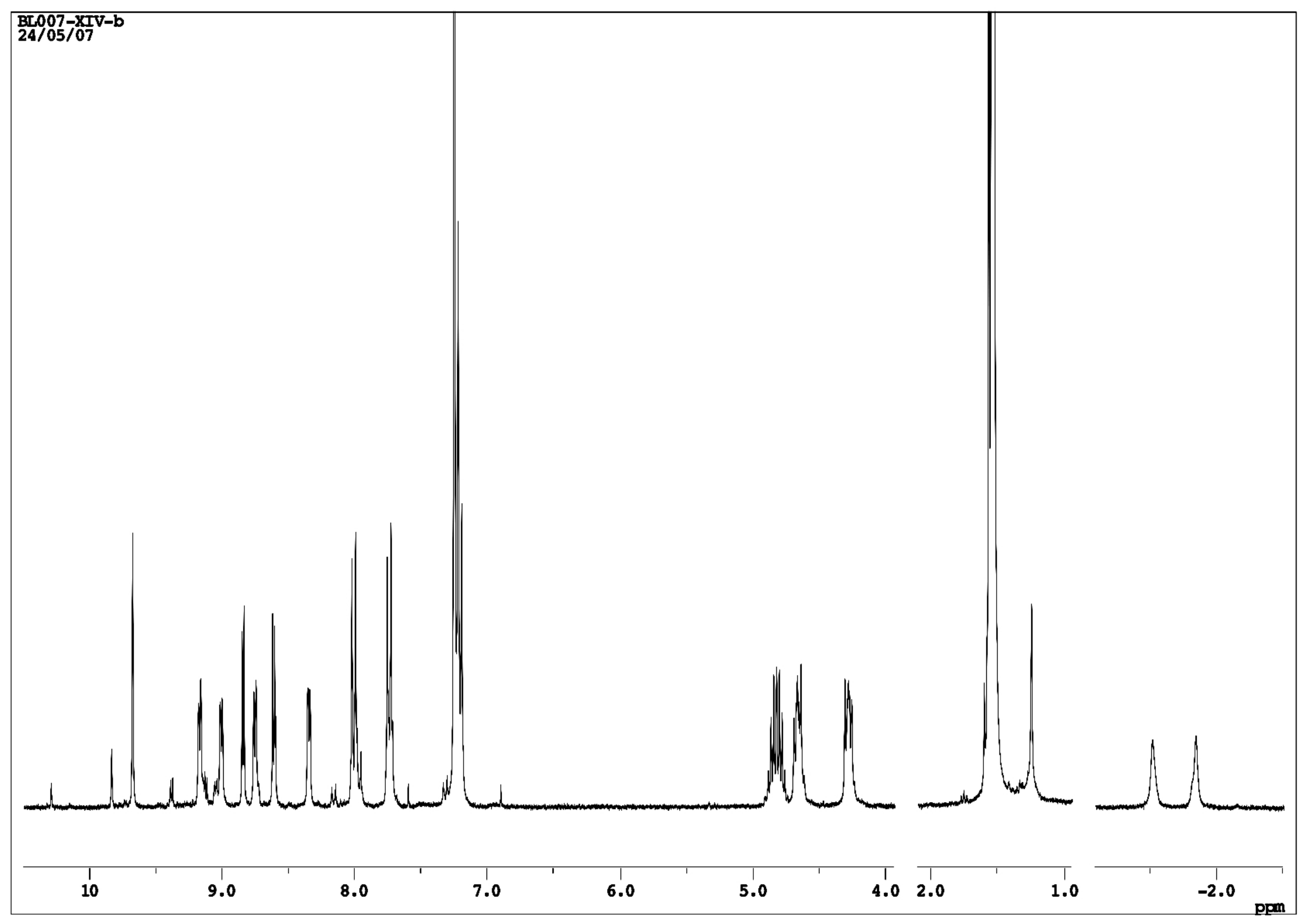

${ }^{1} \mathrm{H}$ NMR spectrum of chlorin $\mathbf{7 b}$ in $\mathrm{CDCl}_{3}$ 


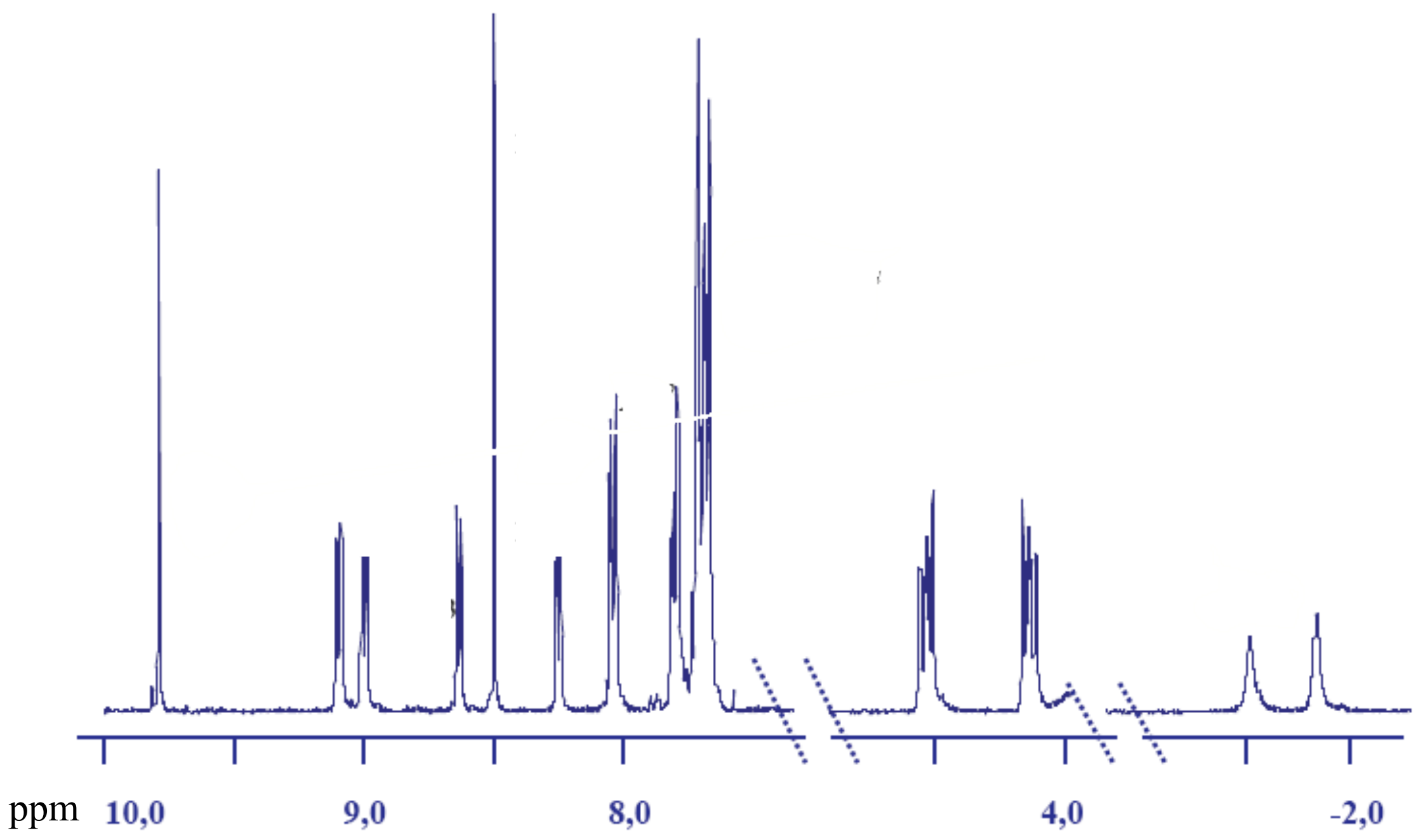

${ }^{1} \mathrm{H}$ NMR spectrum of chlorin $\mathbf{8 a}$ in $\mathrm{CDCl}_{3}$ 


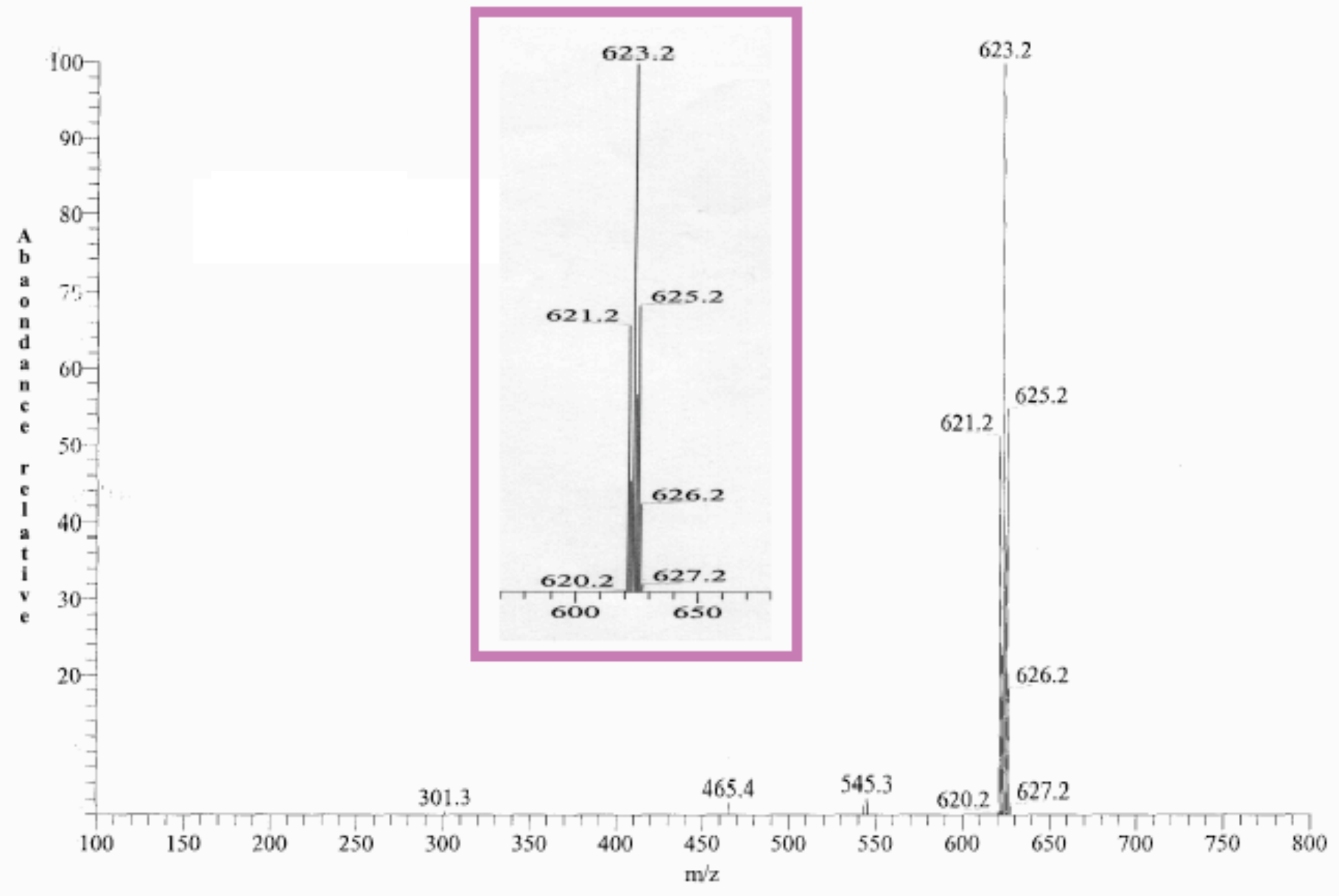

MALDI-TOF mass spectrum of chlorin $\mathbf{8 a}$ 


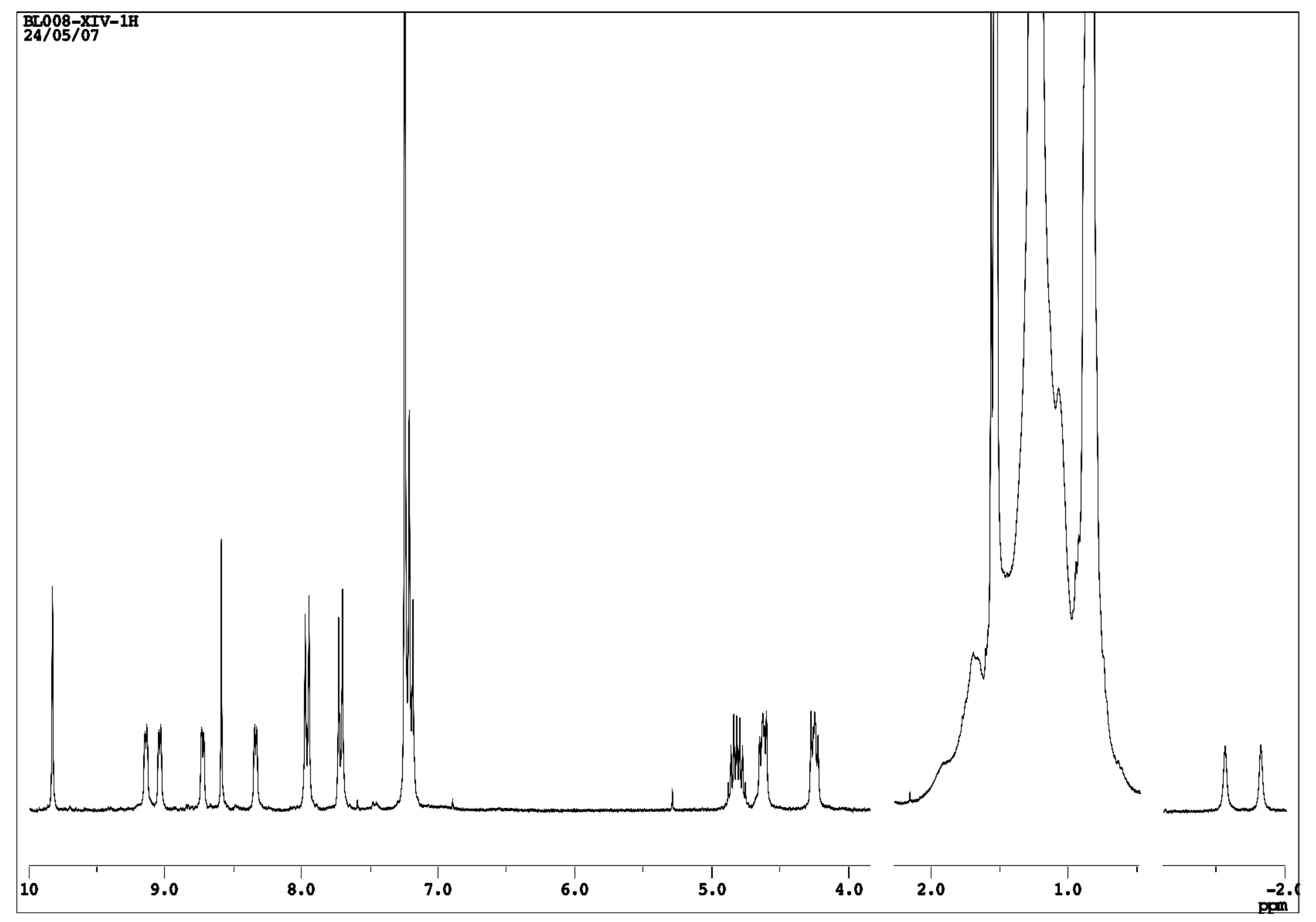

${ }^{1} \mathrm{H}$ NMR spectrum of chlorin $\mathbf{8 b}$ in $\mathrm{CDCl}_{3}$ 


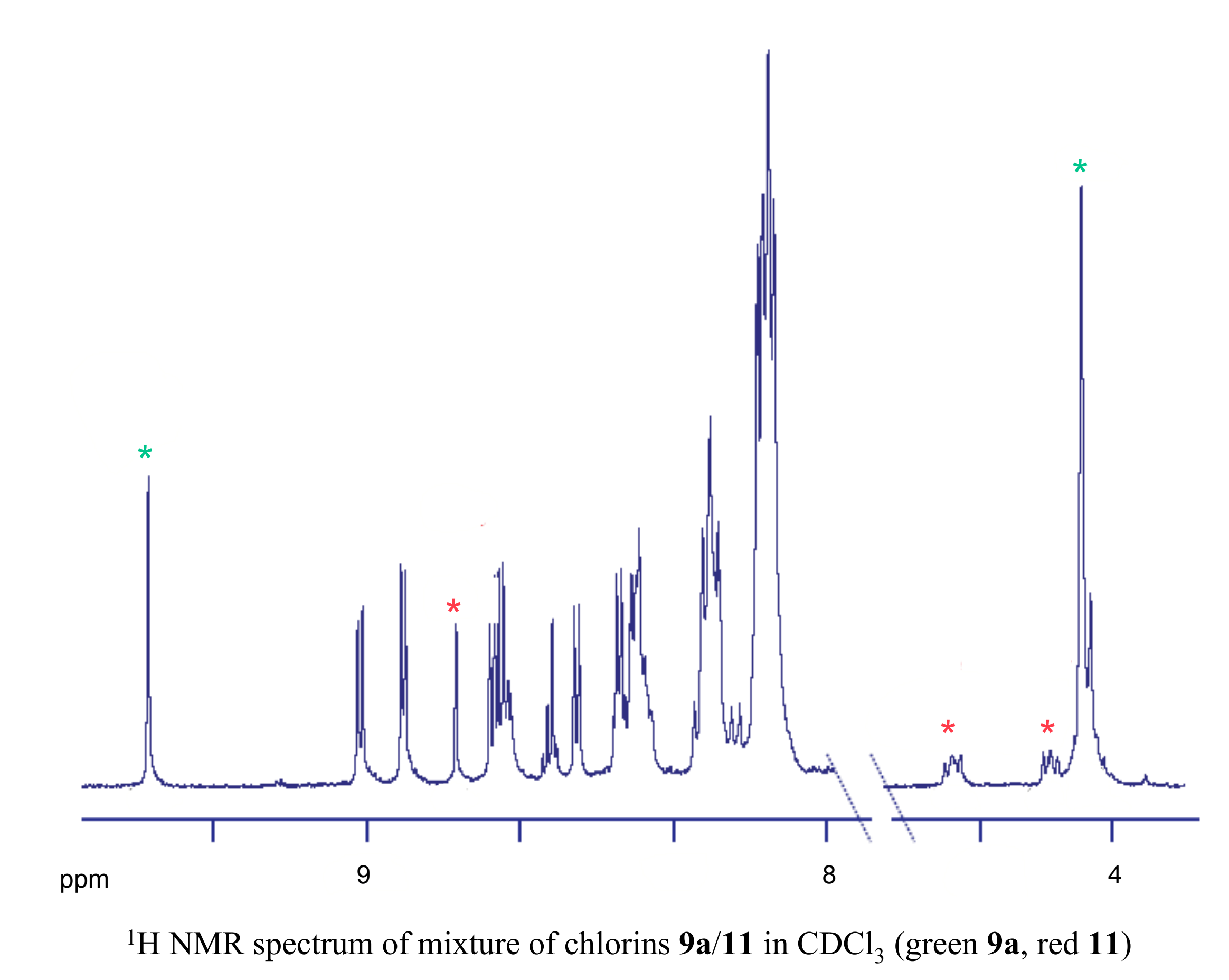




$$
\text { (it) II }
$$




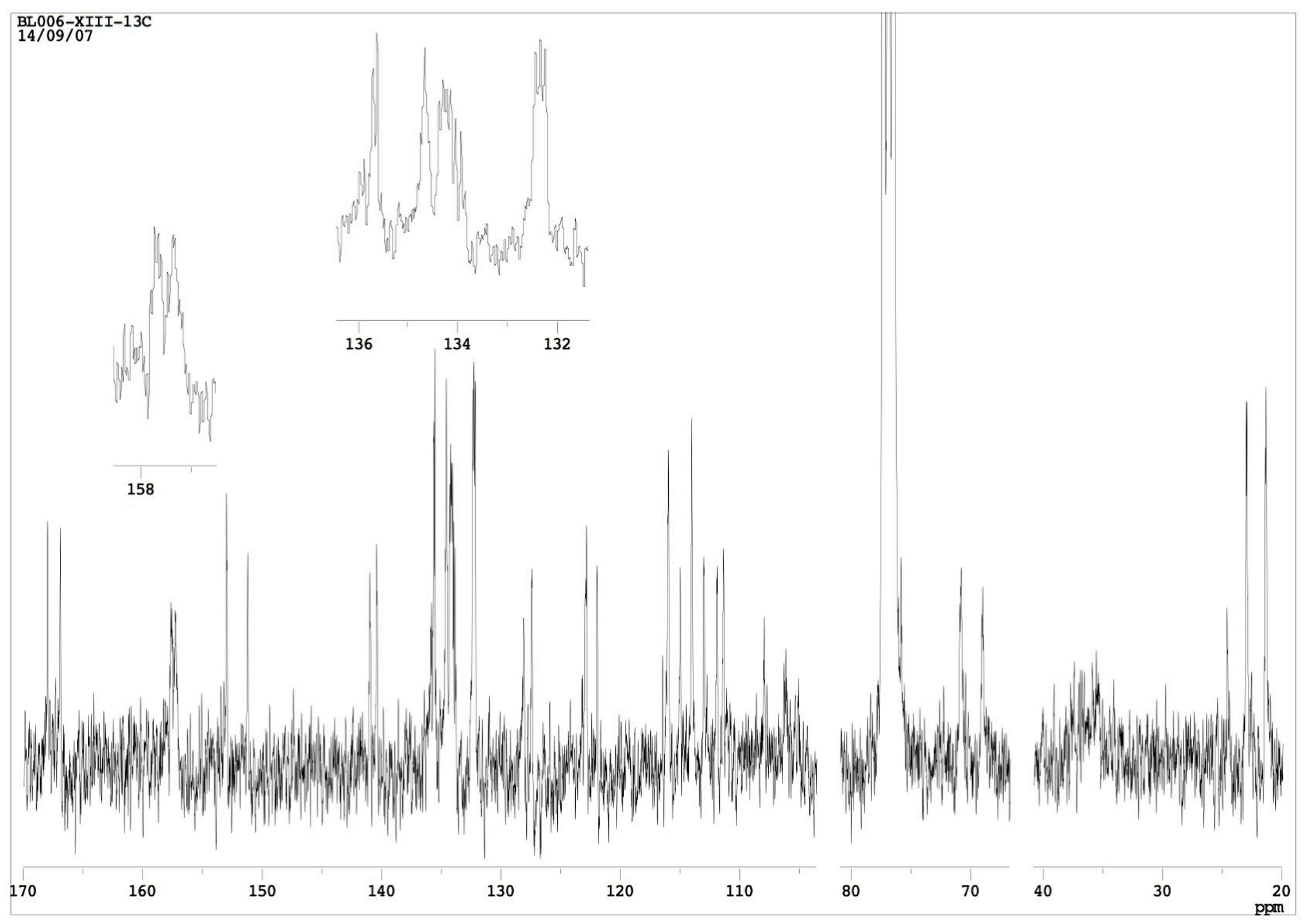

${ }^{13} \mathrm{C}$ NMR spectrum of chlorin $9 \mathbf{b}$ in $\mathrm{CDCl}_{3}$ 


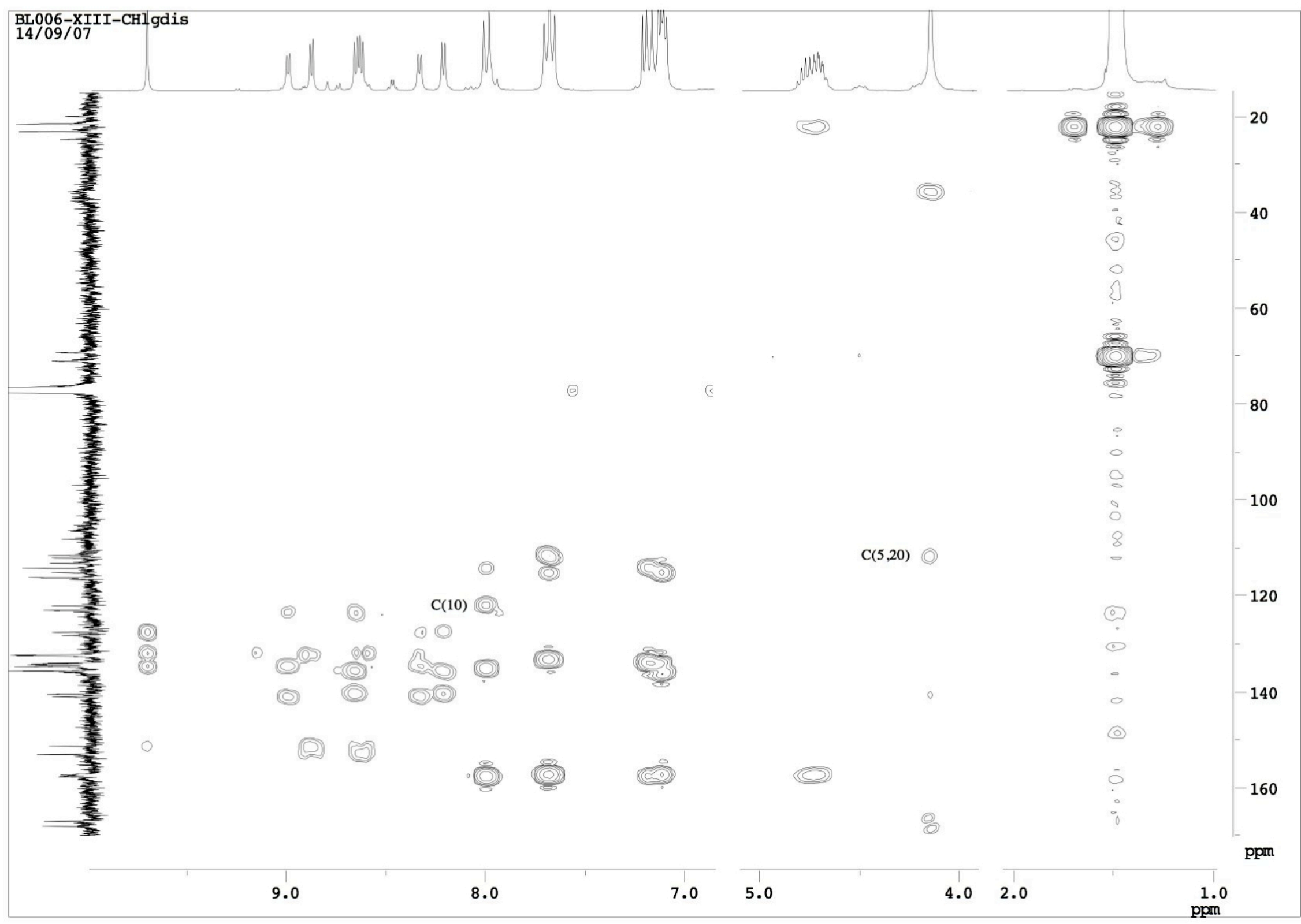

2D NMR spectrum (HMBC) of chlorin $\mathbf{9 b}$ in $\mathrm{CDCl}_{3}$ 


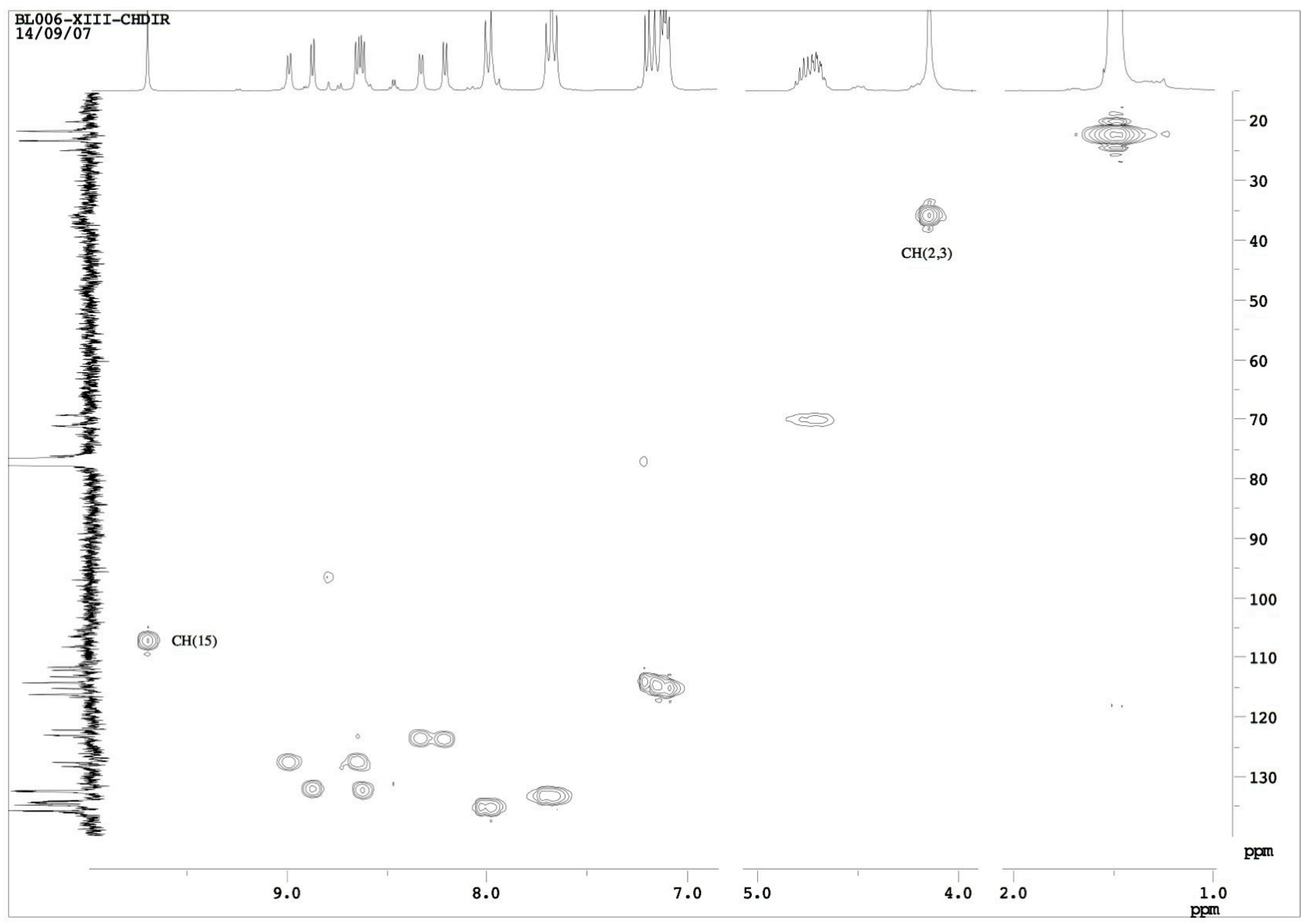

2D NMR spectrum (HMQC) of chlorin $9 \mathbf{b}$ in $\mathrm{CDCl}_{3}$ 


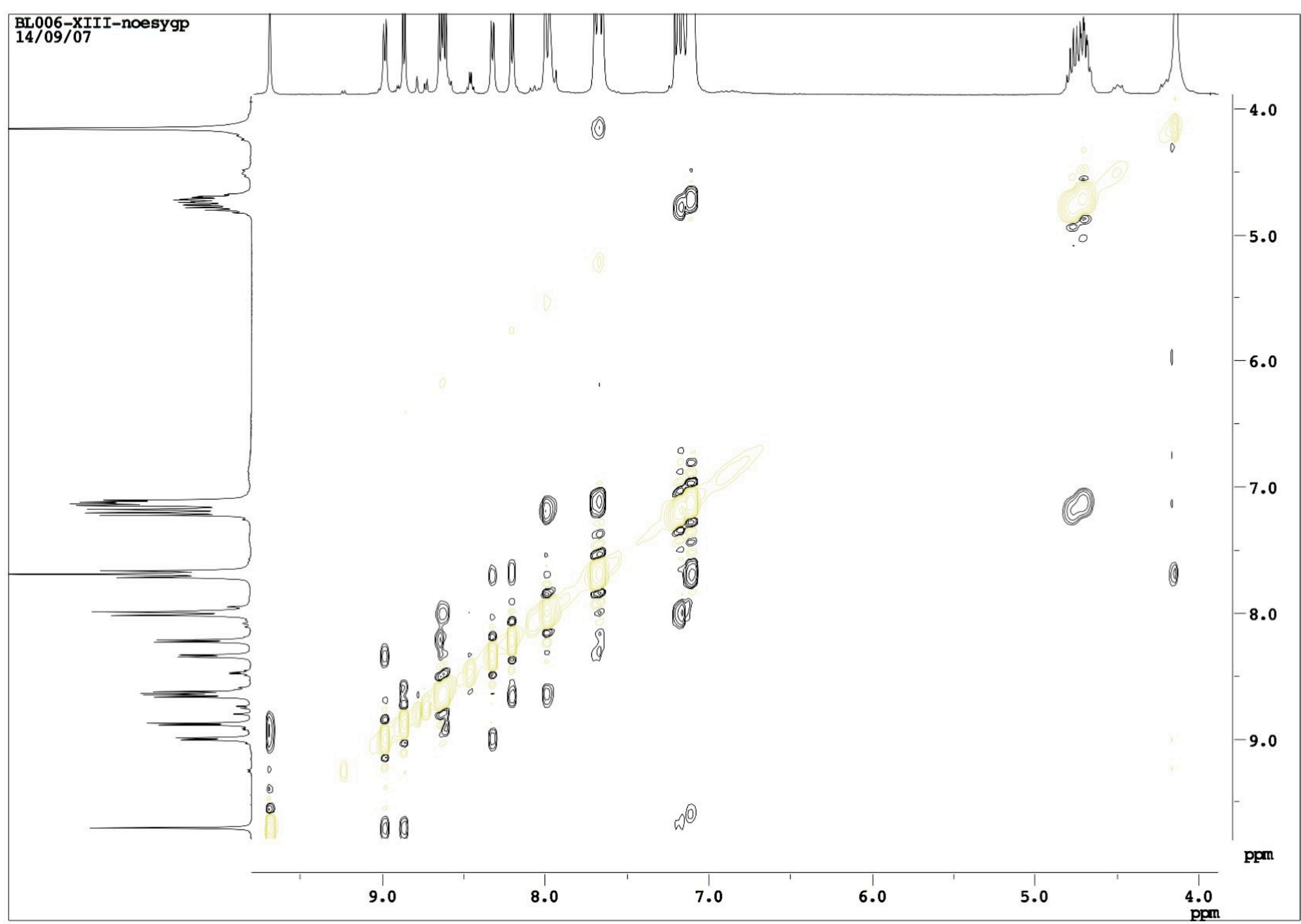

2D NMR spectrum (NOESY) of chlorin $9 \mathbf{b}$ in $\mathrm{CDCl}_{3}$ 


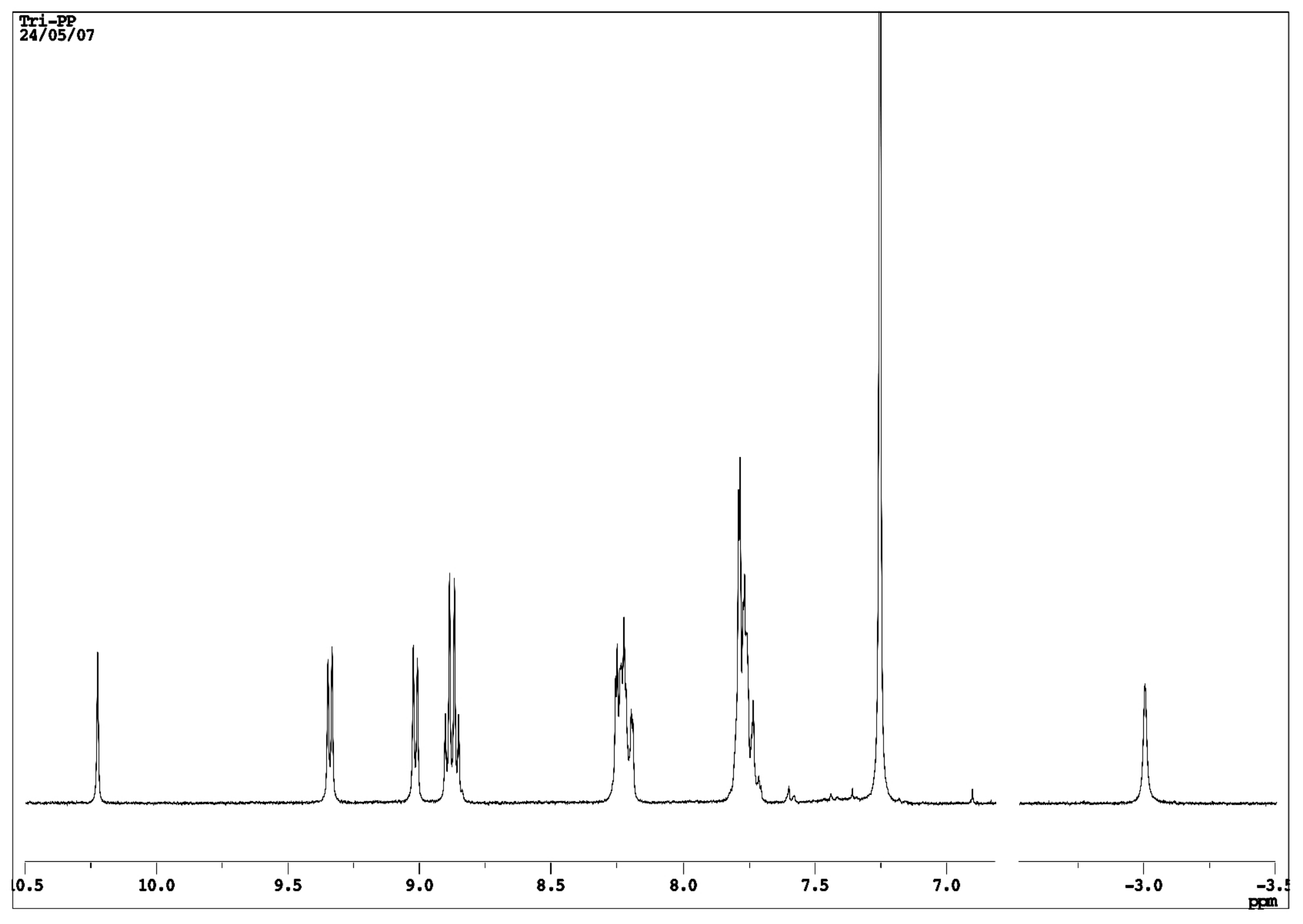

${ }^{1} \mathrm{H}$ NMR spectrum of chlorin $\mathbf{1 0}$ in $\mathrm{CDCl}_{3}$ 


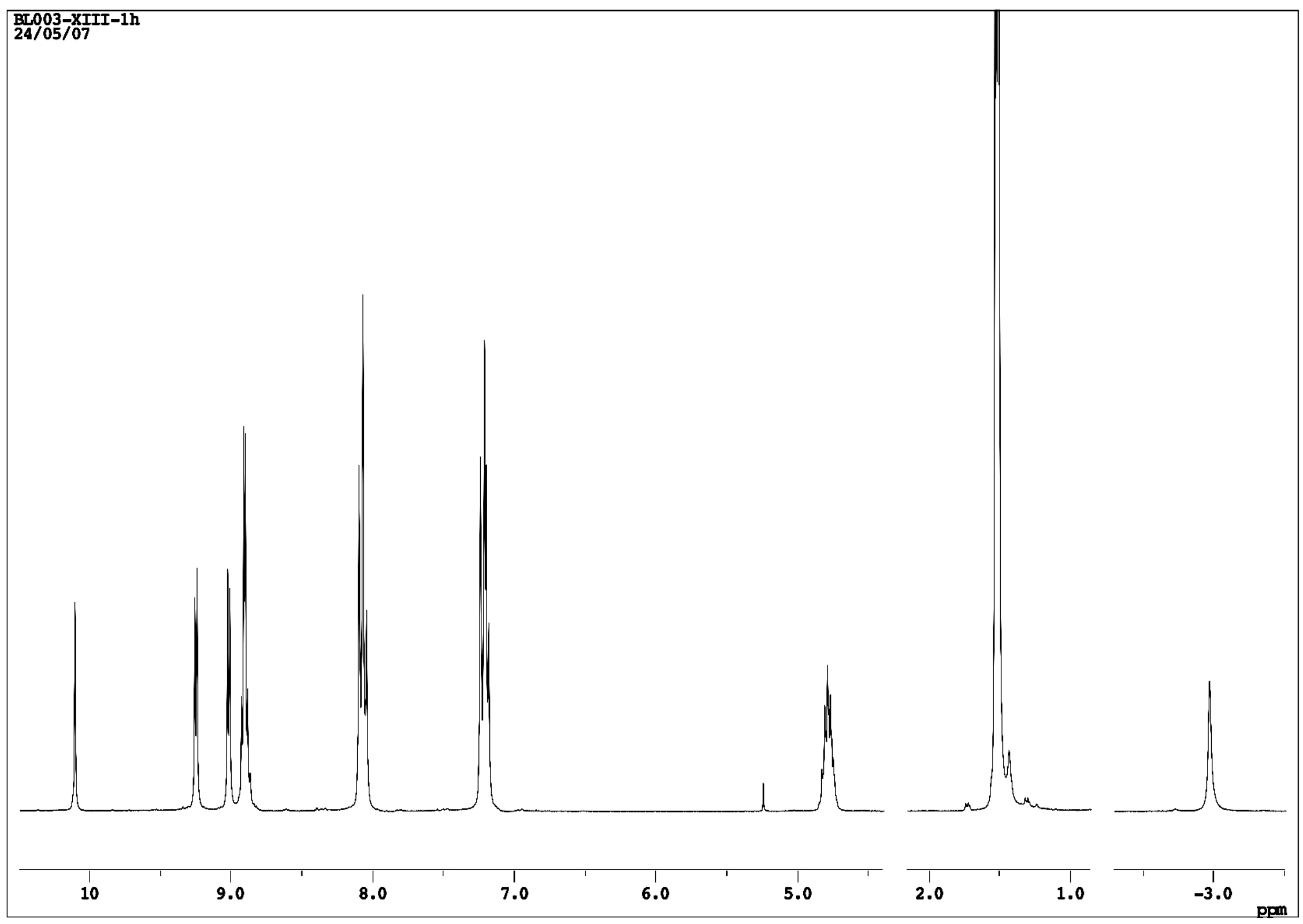

${ }^{1} \mathrm{H}$ NMR spectrum of chlorin 13 in $\mathrm{CDCl}_{3}$ 


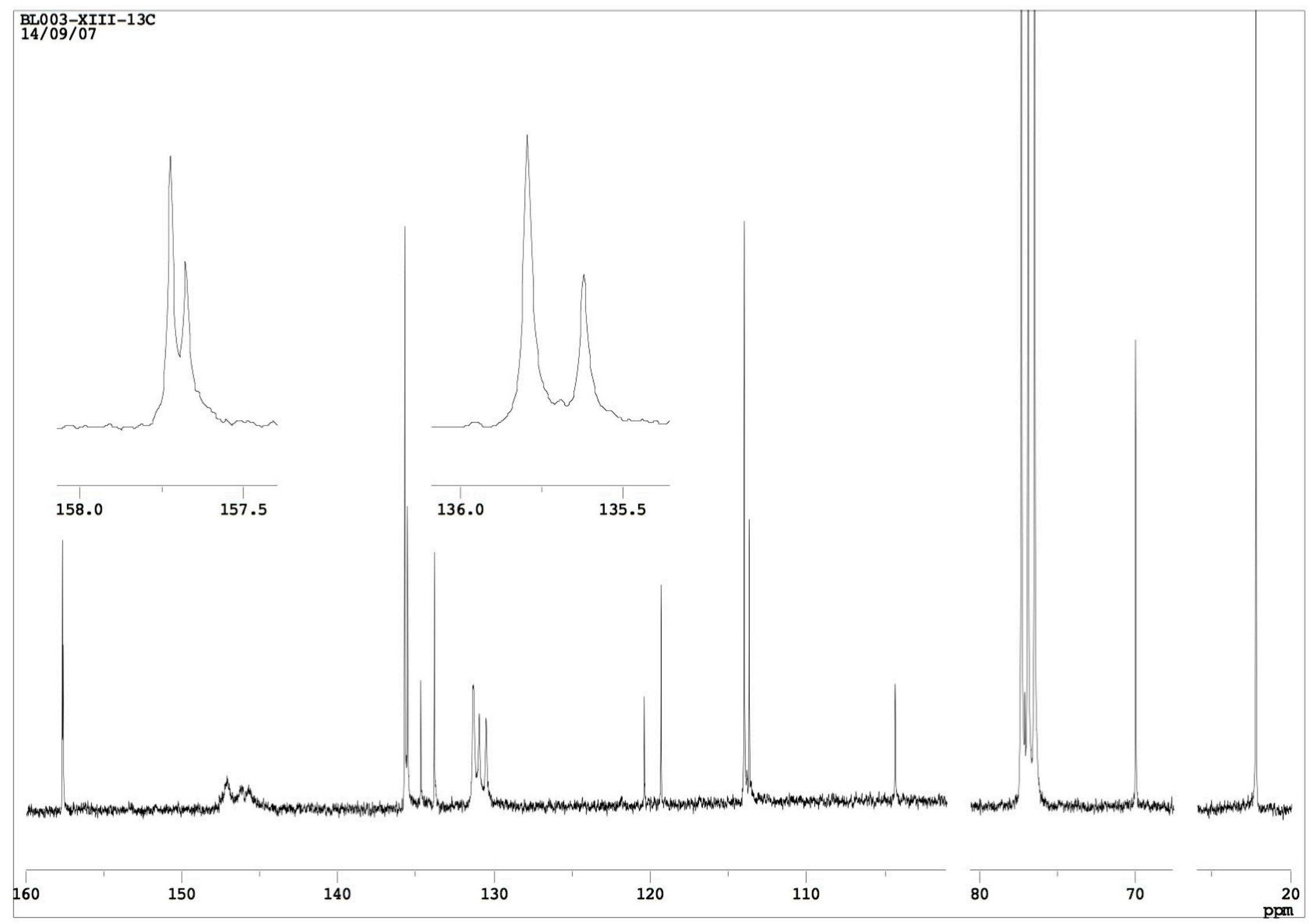

${ }^{13} \mathrm{C}$ NMR spectrum of chlorin 13 in $\mathrm{CDCl}_{3}$ 


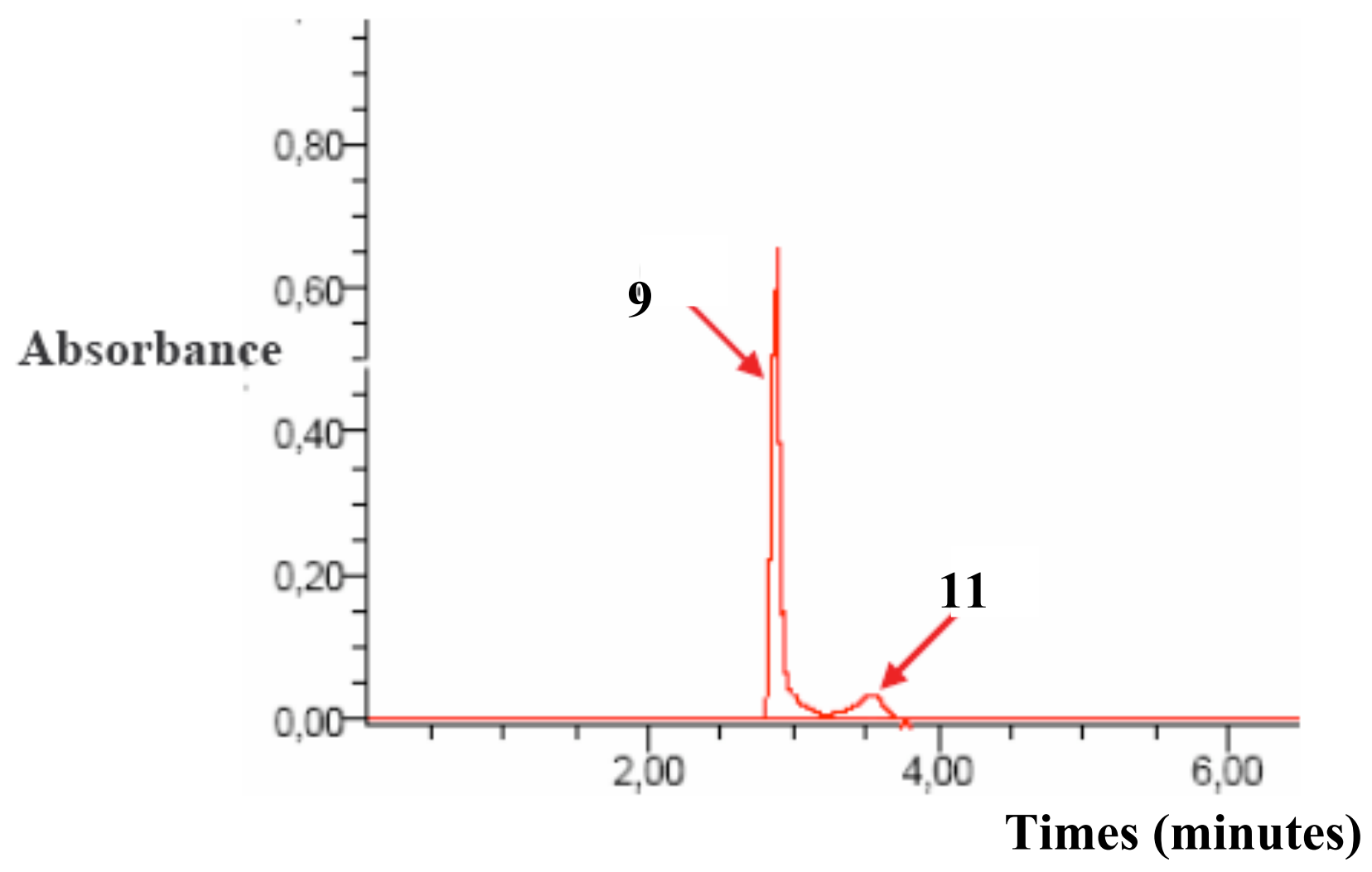

HPLC chromatogram of mixture of chlorins 9a and 11, Apparatus : Waters P600 PDA-996, column : Lichrospher $100 \mathrm{SiO}_{2} 5 \mu \mathrm{m}$, 250x4, Solvents : methylene chloride/heptane, 1/1, v/v, $1 \mathrm{~mL} / \mathrm{min}$. 